\title{
Substance Use, HIV Serostatus Disclosure, and Sexual Risk Behavior in People Living with HIV: An Event-level Analysis
}

Matthew Sullivan

matthew.c.sullivan@uconn.edu

\section{Recommended Citation}

Sullivan, Matthew, "Substance Use, HIV Serostatus Disclosure, and Sexual Risk Behavior in People Living with HIV: An Event-level Analysis" (2018). Master's Theses. 1278.

https://opencommons.uconn.edu/gs_theses/1278 
Substance Use, HIV Serostatus Disclosure, and Sexual Risk Behavior in People Living with HIV: An Event-level Analysis

\author{
Matthew Sullivan \\ B.A., Williams College, 2011
}

\author{
A Thesis \\ Submitted in Partial Fulfillment of the \\ Requirements for the Degree of \\ Master of Science \\ at the \\ University of Connecticut
}

2018 


\section{Copyright by}

\section{Matthew Sullivan}




\section{APPROVAL PAGE}

Master of Science Thesis

Substance Use, HIV Serostatus Disclosure, and Sexual Risk Behavior in People Living with HIV: An Event-level Analysis

Presented by

Matthew C. Sullivan, B.A.

Major Advisor

Dean G. Cruess, Ph.D.

Associate Advisor

Seth C. Kalichman, Ph.D.

Associate Advisor

Tania B. Huedo-Medina, Ph.D.

University of Connecticut

2018 


\section{ACKNOWLEDGEMENTS}

I have many people to thank for their help and support in completing this thesis project. First, I would like to thank Dr. Dean Cruess, my major advisor and research mentor. I am truly fortunate to have received your generous and unfailing mentorship these past few years. Thank you for helping me to succeed every step of the way.

Next, I'd like to thank Dr. Tania Huedo-Medina. Your skillful instruction has been invaluable in demystifying multilevel modeling. Thank you for providing me with the tools necessary to complete this project.

I'd also like to thank Dr. Seth Kalichman. Thank you for the tremendous mentorship you have provided over the last three years, and for generously sharing the data upon which this research is based. It has been a great privilege learning from you each week as a Social Processes of AIDS training fellow. Thank you for opening a world of research opportunities I wouldn't have dreamed of just a few years ago.

I'd also like to thank the study staff and participants without whom this project would not have been possible. Thanks to Moira Kalichman, Chauncey Cherry, Tamar Grebler, and many others.

Thanks also to the National Institute of Mental Health for my training fellowship support (T32-MH074387).

Thanks to my friends and colleagues at UConn for their good humor and encouragement. Thanks in particular to Lucy Finkelstein-Fox for her close read of this manuscript and interminable hours discussing multilevel modeling.

I'd also like to thank Dr. Ari Solomon for encouraging me to pursue graduate research in clinical psychology. Thank you for believing in me, for offering your professional wisdom time and again, and for forever stoking my curiosity in the field. I quite simply wouldn't be where I am today without your mentorship, friendship, and support.

Finally, I want to thank my parents, Peter and Elizabeth Sullivan, for their boundless love and support. Thank you for encouraging me to follow my everincreasingly bookish interests, and for helping me to do so in ways too innumerable to list. 


\section{TABLE OF CONTENTS}

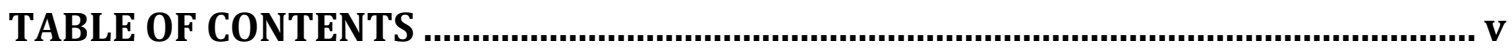

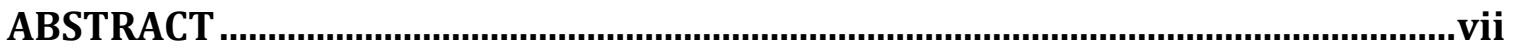

INTRODUCTION ......................................................................................................... 1

Sexual Transmission of HIV/AIDS in the United States...........................................

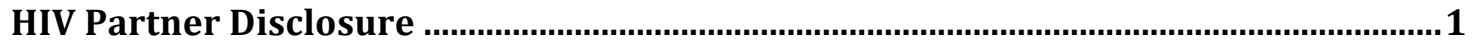

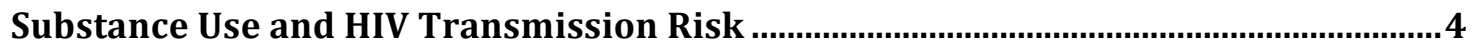

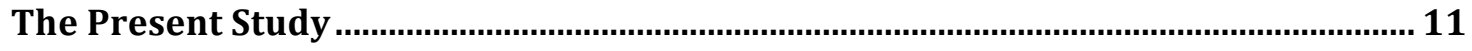

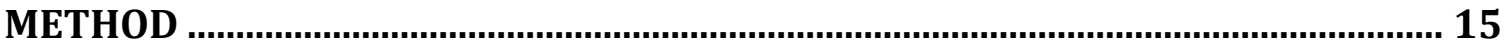

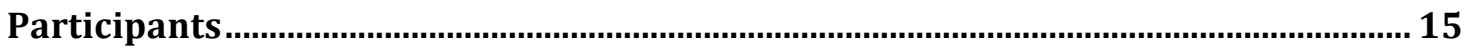

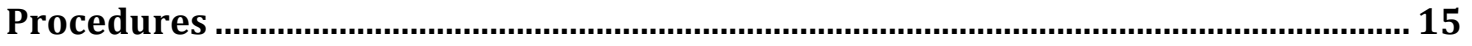

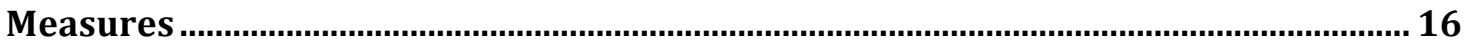

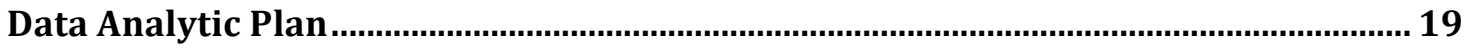

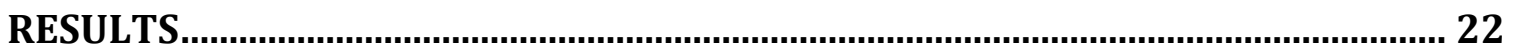

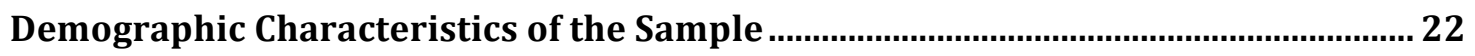

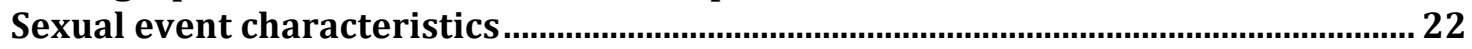

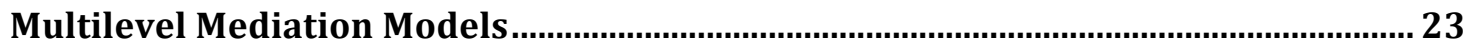

Substance Use and Condom Use (Direct effect) .............................................................. 24

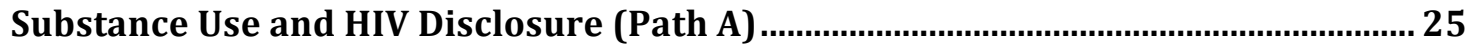

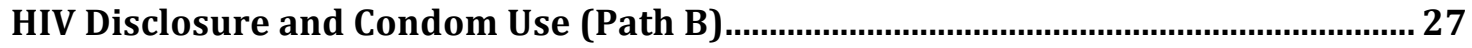

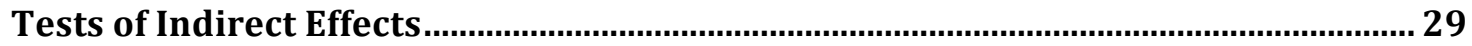

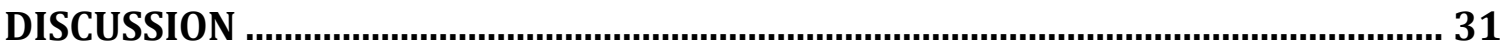

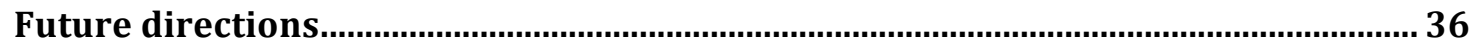

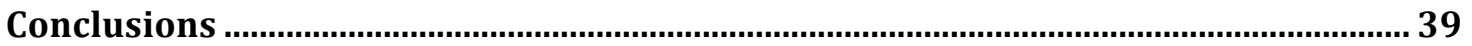

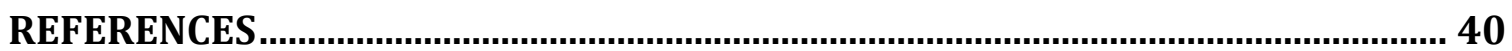

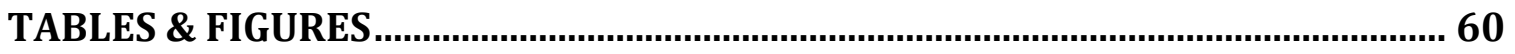

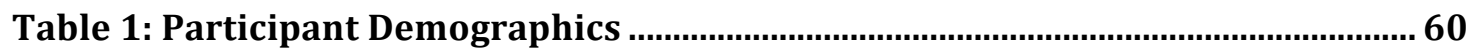

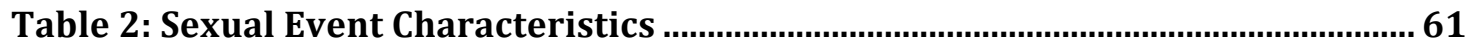

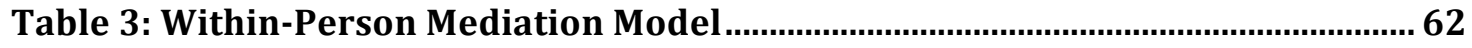

Table 4A: Between-Person Mediation Model-Alcohol Use (AUDIT) ...........................63

Table 4B: Between-Person Mediation Model-Illicit Drug Use (DAST) ...................... 63

Table 4C: Between-Person Mediation Model-Frequency of Using Substances at

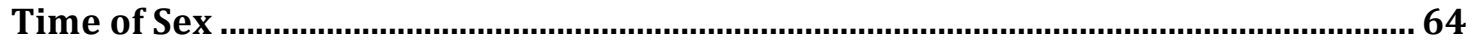

Table 5A: Path A Model Predicting Participant HIV Disclosure from Event-Level

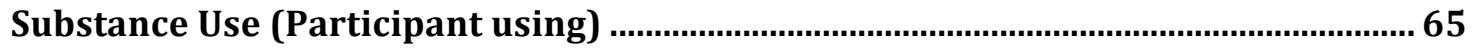

Table 5B: Path A Model Predicting Participant HIV Disclosure from Event-Level

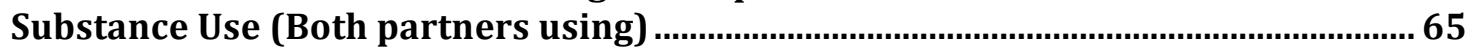

Table 5C: Path A Model Predicting Participant HIV Disclosure from Event-Level

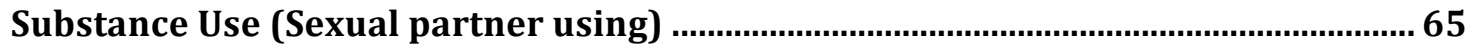

Table 6: Path B Model Predicting Condom Use from Event-Level HIV Disclosure ... 66

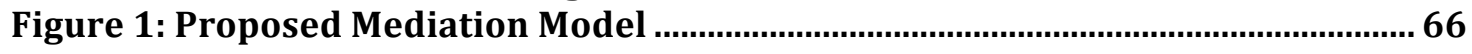

APPENDIX: MPlus Code for Event-Level Analyses ...............................................67

Within-Person Mediation Model (Results Reported in Table 3)................................... 67 
Between-Person Mediation Model (Results Reported in Tables 4 A-C)

Path A Model Predicting Participant HIV Disclosure from Event-Level Substance

Use (Results Reported in Tables 5 A-C)

Path B Model Predicting Condom Use from Event-Level HIV Disclosure-Within-

Person and Between-person terms included (Results Reported in Table 6) ............. 70

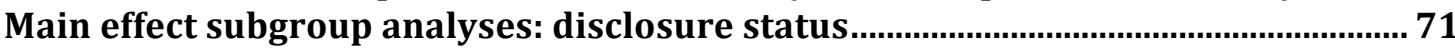

Main effect subgroup analyses by gender and partner gender ................................... 72 


\begin{abstract}
Objective. HIV remains a highly stigmatized illness in the United States, and many people living with HIV (PLWH) in treatment must make difficult decisions about disclosing their HIV status to sexual partners. Because knowledge of a sexual partner's HIV serostatus can facilitate preventative health measures, an understanding of the factors that affect disclosure decision-making and subsequent condom use behavior may help to design effective interventions. Alcohol and illicit drug use are prevalent in PLWH engaged in medical care, and could impact these decision-making processes. We sought to examine the acute relationships between substance use, HIV serostatus disclosure, and condom use on an event-level basis. Method. Men and women living with HIV were recruited from community services and infectious disease clinics in a southeastern US city. Participants reported on demographic information and psychosocial and physical health variables via audiocomputer assisted self-interviews (ACASI) at study entry, and completed a urine drug toxicity screen. Participants also reported daily sexual behavior for 28 consecutive days via daily interactive text message prompts. Daily reports specified whether anal or vaginal intercourse occurred, whether with a first-time sexual partner, whether the participant disclosed their HIV-positive serostatus, whether the participant ascertained their partner's HIV status, whether the participant and/or their partner used substances prior to intercourse (including alcohol or other drugs), and whether a condom was used. We employed multi-level modeling to evaluate the event-level associations between substance use, HIV serostatus
\end{abstract}


disclosure, and condom use in all first-time sexual encounters involving sexual partners whose HIV serostatus was HIV-negative or unknown.

Results. Out of a larger study sample, 251 participants (85\% male, 92\% African American) reported engaging in anal or vaginal intercourse with a first-time sexual partner whose HIV status was negative or unknown, with a total of 529 first-time partners reported during the study period (mean=2.11 partners). At the event level, substance use at the time of sex did not predict odds of condom use among inconsistent condom users ( $\mathrm{p}>0.05)$; however, on average, heavier alcohol users tended to be those most likely to engage in condomless sex ( $\mathrm{p}=0.01)$. Participants disclosed their HIV serostatus to only $32 \%$ of first-time non-HIV-positive sexual partners. Event-level substance use negatively predicted HIV serostatus disclosure across the 28-day study period (odds ratio=0.46; $\mathrm{p}=0.04$ ). Disclosure was more frequent among consistent condom users than those who consistently engaged in condomless sex $(\mathrm{p}<0.01)$, yet disclosure was not related to increased condom use among inconsistent condom users at the event level $(\mathrm{p}>0.05)$.

Conclusions. This study demonstrates that substance use just prior to intercourse is associated with decreased HIV serostatus disclosure in PLWH. This is the first study to use multilevel modeling techniques to examine the relationship between substance use and HIV serostatus disclosure at the daily event level. Substance using PLWH may benefit from interventions designed to moderate substance use or enhance behavior skills for reducing HIV transmission risk when using substances. 


\section{INTRODUCTION}

\section{Sexual Transmission of HIV/AIDS in the United States}

With over 1.2 million people currently living with HIV (PLWH) in the United States, HIV continues to contribute to major health disparities (Center for Disease Control and Prevention, 2016) . Over 90\% of new infections in 2016 were attributable to sexual contact, with marked disparities in incidence by race, income, gender, and sexual identity. Men who have sex with men (MSM) accounted for a disproportionate two-thirds of new diagnoses in 2016, and HIV incidence continues to rise in Black and Latino MSM (Center for Disease Control and Prevention, 2017) . Despite significant advances in available HIV treatment and prevention options (e.g., highly active antiretroviral therapy (HAART) and Pre-Exposure Prophylaxis (PrEP)), efforts have failed to curb sexual transmission of HIV. Thus, efforts to understand and modify health-related behaviors remain crucial for HIV prevention.

\section{HIV Partner Disclosure}

Disclosure of positive HIV serostatus enables sexual partners of PLWH to make informed choices regarding acceptable levels of HIV transmission risk. As such, sexual partner disclosure has been targeted as an important component of prevention interventions in PLWH (Chiasson, Shaw, Humberstone, Hirshfield, \& Hartel, 2009; Conserve, Groves, \& Maman, 2015; Kalichman et al., 2001; Serovich, Laschober, Brown, \& Kimberly, 2017) . Such interventions propose that if non-HIV- 
positive sex partners are informed of their acute risk of HIV transmission, they will be more motivated to implement HIV prevention strategies such as condom use.

Decisions concerning whether to disclose positive HIV status are complicated by the highly charged social and legal context in which they occur (Parsons, VanOra, Missildine, Purcell, \& Gómez, 2004; Parsons, Schrimshaw, Bimbi et al., 2005) . Given that disclosure affords sex partners of PLWH the opportunity to make more informed decisions concerning their acceptable levels of HIV risk, some public health officials have argued that HIV disclosure is a moral imperative, with PLWH possessing a "duty to warn" (Marks \& Crepaz, 2001; Stein et al., 1998) . In many US states, this stance has been codified into law; approximately half of states currently impose criminal penalties for non-disclosure of positive HIV status to sexual partners (Lehman et al., 2014) . Research indicates that many PLWH believe themselves to be personally responsible for preventing potential HIV transmission to their sexual partners (Serovich \& Mosack, 2003; Wolitski, Bailey, O'Leary, Gómez, \& Parsons, 2003) . Yet despite legal repercussions and public health strategies designed to increase HIV disclosure in PLWH, non-disclosure of HIV status to sexual partners occurs frequently. One probability sample of PLWH in medical care found that $42 \%$ of MSM, $19 \%$ of heterosexual men, and $17 \%$ of heterosexual women living with HIV reported having sex without disclosing (Ciccarone et al., 2003; Serovich \& Mosack, 2003) .

Reasons for non-disclosure of HIV status vary. HIV remains a highly stigmatized illness in the United States, and the large majority of PLWH engaged in care endorse internalized negative attitudes regarding HIV (Baugher et al., 2017) . 
The competing consequences theory of disclosure suggests that PLWH tend to disclose their HIV status in instances in which they appraise the benefits of disclosure to outweigh the perceived costs (Serovich, 2001) . Thus, PLWH must often weigh the potential HIV prevention benefits against a number of potential costs. Anticipated negative partner reactions and fear of secondary disclosure are each associated with decreased likelihood of disclosure to sexual partners (Baugher et al., 2017; Bird, Eversman, \& Voisin, 2017; Galletly \& Dickson-Gomez, 2009; Przybyla et al., 2013; Smit et al., 2012) . High rates of intimate partner violence following disclosure present serious threats for both MSM and women living with HIV, and risk of victimization is especially high among people who report greatest levels of substance use (Brown, Serovich, \& Kimberly, 2016; Gielen, McDonnell, Burke, \& O'campo, 2000). Thus, low self-efficacy about communicating HIV status to partners as well as anticipated negative consequences of disclosure often hinder disclosure efforts (Bird \& Voisin, 2013; Crawford, Rodden, Kippax, \& Van de Ven, 2001; Serovich \& Mosack, 2003) .

In the face of these significant barriers, many PLWH practice selective disclosure to sexual partners, disclosing their HIV-positive status to some but not others (Bird \& Voisin, 2013; Parsons et al., 2005; Przybyla et al., 2013) . Such decisions require a weighing of the costs and benefits associated with disclosing to a specific sexual partner (Serovich, 2001). Perceptions of partner trustworthiness have been identified as one important determinant of such decisions to disclose (Bird et al., 2017) . A range of research has indicated that serostatus disclosure occurs less frequently with casual as opposed to with regular sex partners, perhaps 
in part because less may be known about the trustworthiness of sexual partners in such encounters (Bird \& Voisin, 2013; Ciccarone et al., 2003; Perry et al., 1994; Przybyla et al., 2013) . Additionally, demand characteristics across a variety of casual sex contexts may further pressure individuals to engage in sex with little prior conversation (Bird et al., 2017; Prestage et al., 2001) . Thus, sexual encounters between PLWH and their non-regular sexual partners are particularly likely to involve uninformed decision-making regarding sexual risk reduction. As such, these encounters pose particularly high risk for HIV transmission. A comprehensive understanding of disclosure decision-making in casual or first-time sexual encounters is therefore valuable for informing HIV prevention strategies. One important factor in decisions to disclose may be substance use.

\section{Substance Use and HIV Transmission Risk}

Use of alcohol and other drugs has been widely studied for its role in understanding HIV transmission risk behavior (Bourne \& Weatherburn, 2017; Bryan, Schmiege, \& Magnan, 2012; Scott-Sheldon et al., 2013) . On average, people who engage in heavier drug and alcohol use are more likely to have condomless anal and vaginal sex, to engage in unprotected sex with a greater number of partners, and to acquire HIV (Cooper, 2002; Koblin et al., 2006a; Reilly \& Woo, 2001; Weinhardt \& Carey, 2000). However, the extent to which these associations are causal or attributable to co-occurring risk factors is less certain. Person-level studies, or those that measure participants' average (global) behavior, cannot observe whether behaviors of interest co-occur at a given time within an individual. By contrast, event-level research has helped to investigate the direct relationship 
between these behaviors by examining whether the likelihood of condomless sex is greater in sexual events where substance use is present. While many such studies have suggested a relationship between substance use and risky sexual behavior, not all event-level studies have observed this substance use-sexual risk link (Bryan et al., 2012; Colfax et al., 2004; Koblin et al., 2006a; Vanable et al., 2004; Vosburgh, Mansergh, Sullivan, \& Purcell, 2012) . Some researchers have also noted that an event-level relationship between substance use and sexual risk behavior does not by itself demonstrate causation, as this relationship may be confounded by situational characteristics of the sexual event (Barta et al., 2008) . Efforts to disentangle this relationship have observed a dose-related relationship of alcohol use with sexual risk-taking in PLWH and in young non-positive MSM, suggesting that a greater number of drinks prior to a sexual event is associated with an increasing likelihood of engaging in condomless sex (Barta et al., 2008; Kahler et al., 2015) .

Differences in personal and situational factors may help to explain the mixed relationships between substance use and sexual risk behavior across event-level studies. While one event-level study found that young MSM were more likely to engage in condomless anal sex with serodiscordant partners on drinking days, a study in adolescent women found no relationship between alcohol or marijuana use and condom use (Hensel, Stupiansky, Orr, \& Fortenberry, 2011; Kahler et al., 2015) . Another study in MSM found that alcohol use had no effect on condom use with primary partners, but greatly increased risk of unprotected sex with non-primary 
sex partners (Vanable et al., 2004) . Thus, the link between substance use and sexual risk appears to be moderated by a number of factors.

The link between substance use and sexual risk behavior is also likely to vary across drug types. Event-level associations appear to be particularly strong in the cases of alcohol use and methamphetamine use, and have also demonstrated increased sexual risk taking associated with marijuana and ecstasy/MDMA use (Bourne \& Weatherburn, 2017; Bryan et al., 2012; Card et al., 2017; Vosburgh et al., 2012) . Event-level research regarding other types of drug use is sparse, although global and situational association studies tend to support consistent links between various classes of drug use and sexual risk taking, including stimulant drug use (crystal meth, crack \& other cocaine), club drug use (methamphetamine, MDMA, ketamine, GHB, poppers), and use of intravenously delivered drugs such as heroin (Colfax et al., 2004; Khan et al., 2013; Mayer, Colfax, \& Guzman, 2006; Mayer, Skeer, O'Cleirigh, Goshe, \& Safren, 2014; Purcell, Parsons, Halkitis, Mizuno, \& Woods, 2001; Thiede et al., 2009) . Of note, these global associations between substance use and sexual risk taking have been observed in a number of populations at highest risk for acquiring or transmitting HIV in the US, including MSM receiving medical treatment for HIV, non-HIV-positive MSM, and young adult men and women (Bruce, Kahana, Harper, Fernandez, \& ATN, 2013; Jones-Webb, Smolenski, Brady, Wilkerson, \& Rosser, 2013; Mayer et al., 2014; Patrick, O’Malley, Johnston, Terry-McElrath, \& Schulenberg, 2012; Reilly \& Woo, 2001; Scott-Sheldon et al., 2013) .

Why does substance use increase sexual risk behavior? 


\section{Physiological effects of substance use on sexual risk behavior}

Researchers have identified multiple pathways by which substance use may confer increased risk of sexual transmission of HIV. One such pathway is the direct physiological effect of a substance such as alcohol on executive function and decision-making processes (Day, Kahler, Ahern, \& Clark, 2015; Simons, Maisto, Wray, \& Emery, 2016) . Traditional sociocognitive frameworks for understanding sexual risk behavior hold that people make decisions based on a number of key appraisals. For instance, the Theory of Planned Behavior holds that people make behavioral decisions based on their attitudes regarding a given behavior (e.g., "Do I consider using condoms to be important? Unpleasant?"), perceived social norms regarding the behavior (e.g., "Do others like me usually use condoms?"), and the perceived degree of control they feel they have over performing the behavior (e.g., “Can I successfully negotiate condom use with my sexual partner?”) (Ajzen, 2002; Albarracin, Johnson, Fishbein, \& Muellerleile, 2001) . Yet while these cognitive appraisals have been shown to predict behavioral intentions and subsequent HIV transmission risk behaviors, such assessments of risks and benefits are unlikely to remain stable in the "heat of the moment" when substance use is involved (Davis et al., 2016) .

Alcohol myopia theory has suggested one explanation for alcohol's interference with typical appraisal-based behavior patterns. According to alcohol myopia theory, the acute pharmacological effects of alcohol produce impairment in executive functioning, therefore altering the cognitive processes underlying behavioral decision-making (Field, Wiers, Christiansen, Fillmore, \& Verster, 2010; 
Steele \& Josephs, 1990) . The theory holds that people under the acute influence of alcohol increasingly attend to immediate, impelling cues (such as sexual arousal), and reduce attention to more distant or abstract inhibiting cues (such as the risk of sexually transmitted infections (STIs)) (Steele \& Josephs, 1990; Taylor \& Leonard, 1983). This narrowed attentional focus, in conjunction with increases in subjective sexual arousal, is thought to engender increased willingness to engage in risky sexual behaviors (Day et al., 2015; Simons et al., 2016) .

The extant literature suggests that a similar impaired cognitive processing framework may apply to a number of psychoactive substances beyond alcohol, yet mechanisms of the relationships between drug use and sexual risk taking have been infrequently studied outside of the context of alcohol use (Broyd, van Hell, Beale, Yucel, \& Solowij, 2016; Vosburgh et al., 2012) . Although variation across drug types is expected, event-level research has nevertheless supported links between acute use of other drugs and sexual risk taking. For instance, use of methamphetamine at the time of sex is strongly associated with increased sexual risk taking in MSM (Mansergh et al., 2006) . A few studies examining club drugs such as ecstasy/MDMA, ketamine, and GHB have also shown relationships with increased sexual risk in bivariate, yet not in multivariate analyses (Vosburgh et al., 2012) . By contrast, evidence regarding substances such as nitrite inhalants (i.e., "poppers") and erectile dysfunction drugs has demonstrated mixed or weak associations with sexual risk taking-likely due to differing or negligible effects on cognitive processing (Vosburgh et al., 2012) . Overall, however, studies regarding event-level associations 
SUBSTANCE USE, HIV DISCLOSURE, \& CONDOM USE

between specific classes of psychoactive drug use and sexual risk behavior remain lacking.

\section{Psychological effects of substance use on sexual risk behavior}

In addition to the acute physiological effects substance use on sexual risk behavior, learned expectancies concerning alcohol and other drug use have been found to play important roles in shaping sexual behavior while under the influence (Crowe \& George, 1989; Kalichman, Simbayi, Cain, \& Jooste, 2007; McKirnan, Vanable, Ostrow, \& Hope, 2001; Wells, Golub, \& Parsons, 2011) .

For PLWH who encounter high levels of stress related to their stigmatized HIV diagnosis, substance use may serve as a means of coping with undesirable thoughts and emotions concerning their stigmatized identity (Martin, Pryce, \& Leeper, 2005; Wardell, Shuper, Rourke, \& Hendershot, 2018; Wells et al., 2011) . Commonly held expectancies concerning the anxiety-reducing effects of alcohol and other drugs have been shown to contribute to the likelihood and frequency of substance use behavior (Young et al., 1990; Boys et al., 2001; Parks \& Kennedy, 2004) (Parks \& Kennedy, 2004; Young, OEI, \& Knight, 1990) . Thus, substance use may be conceptualized as a form of disengagement coping; a style of coping characterized by orientation away from stress, as opposed to attempting to influence or change the conditions of a stressor (Carver, Scheier, \& Weintraub, 1989; Compas, Connor-Smith, Saltzman, Thomsen, \& Wadsworth, 2001; Park \& Iacocca, 2014; Yi, Sandfort, \& Shidlo, 2010) .

Such disengagement tactics may serve as a coping strategy both for PLWH and for individuals at risk of acquiring HIV, such as sexually active MSM. In people 
SUBSTANCE USE, HIV DISCLOSURE, \& CONDOM USE

who believe they are at risk of acquiring HIV, substance use has been hypothesized to serve as a means of "cognitive escape" from the perceived threat of HIV (McKirnan, Ostrow, \& Hope, 1996; Wells et al., 2011) . Paradoxically, risky sexual behavior itself has also been suggested to serve as a form of disengagement coping to reduce the anxiety elicited by HIV transmission threat, frequently in conjunction with substance use (Folkman, Chesney, Pollack, \& Phillips, 1992; Martin et al., 2005) .

In PLWH, substance use may serve to facilitate disengagement from a distinct set of threats. PLWH may use substances to disengage from stress associated with the perceived risk of being personally responsible for transmitting HIV to sexual partners. PLWH may also use substance to cope with the perceived risk of negative partner reactions to disclosure of HIV-positive status, with potential consequences including partner rejection, secondary disclosure of one's HIV-positive status, and intimate partner violence (Brown et al., 2016; Serovich \& Mosack, 2003) .

\section{Substance Use and HIV Status Disclosure}

The decision of whether or not to disclose one's HIV-positive status to a sexual partner is a complex social behavior that depends on both personal factors (e.g., disclosure self-efficacy) and situational factors surrounding the sexual event (Bird \& Voisin, 2011; Kalichman \& Nachimson, 1999; Kalichman, Kalichman, Cherry, \& Grebler, 2016) . While a number of situational factors related to HIV partner disclosure have been examined (e.g., meeting venue; sexual partner characteristics), 
the role of substance use in HIV disclosure decision-making is not well understood (Elwood, Greene, \& Carter, 2003; Jones-Webb et al., 2013; Rutledge, 2007).

As previously discussed, acute drug intoxication has been hypothesized to decrease attention to non-immediate social or health-related consequences of behavior (Cusick, 1999; Simons et al., 2016; Steele \& Josephs, 1990) . Moreover, given widely shared beliefs that substance use impairs decision making, substance use has also been hypothesized to serve as a social "excuse" for nondisclosure, enabling denial of personal agency during sexual encounters due to a presumed decreased in awareness and judgment (Crowe \& George, 1989; Cusick, 1999; MacAndrew \& Edgerton, 1969) . A recent study found that men living with HIV who had engaged in nondisclosed condomless sex with a non-HIV-positive partner in the past month were more likely to report having used drugs or alcohol before sex (Kalichman et al., 2016) . Qualitative research, by contrast, has suggested a social lubricant effect of substance use, reporting instances in which substance use before sex has been reported to facilitate disclosure, with some individuals "blurting out" their HIV status while "high" (Cusick, 1999) . Yet analyses that do not distinguish between-person differences in behavior from within-person relationships between behaviors are vulnerable to confounding.

\section{The Present Study}

To date, little research has examined the role of substance use within the context of sexual partner HIV disclosure. The few existing studies have examined only between-person differences in substance use behavior, and therefore provide limited insight into the event-level relationship between acute substance use 
intoxication and disclosure. The present study uses a multi-level modeling approach to isolate and examine the event-level correlates of HIV disclosure across a number of sexual events within a sample of PLWH. Implications of event-level substance use and HIV serostatus disclosure for condom use behavior are also examined.

The present study observes PLWH's reported sexual behavior within a onemonth daily prospective observational study. Sexual events of interest were those in which participants reported anal or vaginal sex with first-time sexual partners whose HIV serostatus was HIV-negative or unknown. The study examined sexual events with new sexual partners, rather than longer-term primary partners, due to the especially risky nature of such encounters; PLWH tend to engage in greater sexual risk behavior with non-primary sexual partners, with whom they may feel less comfort, agency, and responsibility disclose their stigmatized identity or negotiate condom use (Bird et al., 2017; Cusick, 1999; Kalichman \& Nachimson, 1999) . Moreover, prior event-level research has found that alcohol use is related to a higher likelihood of condom-unprotected sex with non-primary partners but not with primary partners (Vanable et al., 2004) . Thus, an understanding of HIV risk behavior in the context of first-time sexual encounters is of particular importance for prevention efforts.

While some qualitative reports suggest that disinhibiting effects of substance use may facilitate HIV partner disclosure, both executive impairment theories (e.g., alcohol myopia theory) and substance use expectancy theories (e.g., disengagement coping) suggest that substance use may reduce the likelihood of PLWH disclosing their HIV status prior to sex (Steele \& Josephs, 1990; Wells et al., 2011) . 
SUBSTANCE USE, HIV DISCLOSURE, \& CONDOM USE

Sociocognitive theories such as the Theory of Planned Behavior and the Information-Motivation-Behavioral skills (IMB) model further suggest that this decreased information concerning one's HIV transmission risk is likely to reduce the likelihood of engaging in risk reduction behavior such as condom use (Ajzen, 2002; Fisher \& Fisher, 1992) . Thus, we hypothesized that decreased likelihood of disclosure may be one mechanism by which substance use confers increased risk of HIV transmission.

Multilevel mediation was conducted to examine the relationships between substance use, HIV partner disclosure, and condom use as it varies at the average, between-person level and at the daily event level (Figure 1). We proposed first to test a main effect of event-level substance use on condom use. We then chose to examine HIV serostatus disclosure as a mediator of the relationship between substance use and condom use.

\section{Specific hypotheses}

H1: We hypothesize that substance use at the time of sex use will be associated with a decreased likelihood of condom use with first-time sexual partners whose serostatus is HIV-negative or unknown.

H2: We hypothesize that substance use at the time of sex will be associated with decreased likelihood of HIV serostatus disclosure to first-time sexual partners whose serostatus is HIV-negative or unknown. 
SUBSTANCE USE, HIV DISCLOSURE, \& CONDOM USE

H3: We further hypothesize that nondisclosure of HIV serostatus will be associated with a lower likelihood of condom use during sex with first-time sexual partners whose serostatus is HIV-negative or unknown.

H4: We hypothesize that nondisclosure of HIV serostatus will mediate the event-level relationship between substance use and condom use. 


\section{METHOD}

\section{Participants}

Men and women age 18 or older were recruited from community services and infectious disease clinics in Atlanta, Georgia over a 12-month period between 2013 and 2014. Eligible participants had documentation of being HIV-positive. From this sample, this study examined a subsample of men and women who reported anal or vaginal intercourse with one or more first-time sexual partners whose status was HIV- or unknown. Atlanta, Georgia has an annual HIV incidence of 30.3 per 100,000, higher than the mean rate of 19.6 new infections per 100,000 across major US cities. Georgia state law prohibits persons with HIV from engaging in sexual intercourse without informing their sexual partner of their HIV-positive status. Violation of this law carries a felony penalty punishable by imprisonment of up to 10 years [Ga. Code Ann. x 16-5-60(c)]. Awareness of this law among participants was not assessed.

\section{Procedures}

Targeted community sampling was used to recruit participants, including both venue recruitment and snowball sampling methods. Study brochures were placed in waiting rooms of HIV service providers and infectious disease clinics throughout metropolitan Atlanta. Over $60 \%$ of participants were recruited from a major HIV clinic and outpatient treatment center; the remainder was recruited from a range of private and public health service providers. 
SUBSTANCE USE, HIV DISCLOSURE, \& CONDOM USE

Participants were provided informed consent at the initial office study assessment before reporting demographic and health information via audiocomputer assisted self-interview (ACASI). Such computer interviews have been shown to increase reporting of socially sensitive behaviors such as drug use and sexual behavior (Gribble et al., 2000; Morrison-Beedy, Carey, \& Tu, 2006) . Participants also provided urine samples for drug toxicity screening.

Over the following month, participants reported their sexual behavior prospectively via daily text-message surveys. Past day sexual behavior surveys were completed for 28 consecutive days on study-provided cell phones. Antiretroviral medication adherence was assessed by means of unannounced pill counts (Kalichman et al., 2007). Participants were provided $\$ 145$ for completing all study assessments. All study procedures were approved by the university Institutional Review Board. Study participants were protected by a Federal certificate of confidentiality.

\section{Measures}

Time-invariant measures

Computer-assisted self-interviews for demographic and health information

Using ACASI, participants reported on their age, gender, years of education, employment status, race/ethnicity, and the year they first tested HIV-positive. Participants indicated whether they were currently on antiretroviral therapy (ART), and noted whether they were aware of their most recent viral load test results.

Participants reported on their global alcohol use using the 10-item Alcohol Use Disorders Identification Test (AUDIT) (Saunders, Aasland, Babor, De la Fuente, 
Juan R, \& Grant, 1993) . The AUDIT asks participants to denote their alcohol use quantity and frequency in the past month, in addition to other indicators of problematic alcohol use.

The 10-item version of the Drug Abuse Screening Test (DAST-10) was used to assess participants' global drug use behavior (Skinner, 1982). The measure asked participants to respond "Yes" or "No" to 10 questions regarding the participant's non-alcohol drug abuse behavior during the past 3 months. The 10item version of the DAST has demonstrated acceptable internal consistency (Cronbach's alpha $>.85)$ and test-retest reliability $(r>.70)$ (Cocco \& Carey, 1998) .

Participants were also asked to report on their current depression symptoms using the Center for Epidemiological Studies Depression questionnaire (CES-D) (Radloff, 1977) . The CES-D is a 20-item measure that assesses the presence and severity of depressive symptoms during the past week. The CES-D has been shown to be reliable in previous research (alpha > .85) (Hann, Winter, \& Jacobsen, 1999) .

\section{Drug use screening}

To assess for illicit drug use, an FDA-approved multipanel urine dip-test was administered. This test was used to screen for 12 drugs or their metabolites, including methamphetamine, cocaine, and THC. The test is reliable and valid for initial detection of drug use. A positive result for a given drug indicated current use (Reditest-12; Redwood Toxicology Labs).

Event-level measures

Text message-reported daily behavior 
At the study's initial office assessment, each participant was provided with cell phone and received instruction on how to use the phone's text messaging functions. Over the subsequent 28 days, participants received a prompt by text message to report on their past-day sexual behavior. Daily text message reporting methods have been shown to provide reliable assessment of socially sensitive behaviors (Bernhardt et al., 2009; McAuliffe, DiFranceisco, \& Reed, 2010) . Participants were asked to report whether or not they had sex the previous day; if so, participants were prompted to specify whether they engaged in anal or vaginal sex, whether or not they used a condom, the gender of their partner, whether or not their partner was aware of the participant's HIV-positive status (Told Partner/ Didn't tell but assumed partner knew/Partner didn't know), and whether the participant was aware of their partner's HIV status (Told HIV+/Assume HIV+/Told HIV-/Assume HIV-/Don't Know). Participants also reported whether substances were being used at the time of sex ("I used" /"My partner used" /"Both Used"/ "Neither used"). All responses were coded dichotomously. Only explicit verbal confirmation regarding HIV status was considered to be HIV disclosure (i.e., responses of "Told partner HIV+ status" were considered disclosure, whereas responses of either "Didn't tell but assumed partner knew" and "Partner didn't know" were both coded as nondisclosure). Partner HIV status was also coded dichotomously; participants who responded that their partners "Told that they were HIV+" were coded as HIV+, whereas all other responses, including "Assume HIV+," were coded as "HIV- or unknown." For primary analyses, event-level substance use was defined as either "I used," "My partner used," or "Both used," whereas "Neither 
used" was defined as no substance use. A separate variable was created to examine participant-specific substance use, in which substance use was defined as "I used" or "Both used", and no substance use was defined as "Partner used" or "Neither used." A third substance use variable was created to examine partner-specific substance use; for this variable, substance use was defined as "Partner used" and "Both used," whereas no substance use was defined as "I used" or "Neither used."

\section{Data Analytic Plan}

A multilevel modeling approach was employed to account for the nested structure of the data (i.e., daily sexual events within participants). Data at level 1 were characteristics of the daily sexual event, such as whether substances were used, whether a condom was used, and whether the participant disclosed their HIV serostatus to their partner. Data at level 2 were (time-invariant) participant characteristics, such as participant gender, age, and global drug (DAST) and alcohol use behavior (AUDIT), self-reported at study entry.

For our primary analysis, we tested a two-level random effects mediation model of the within-person relations between event-level (i.e., at the time of sex) substance use, disclosure, and condom use (Figure 1). These models utilized maximum likelihood estimation with robust standard errors to account for the dichotomous nature of the dependent variables. The results of this within-person model are presented in Table 3. Following a test of the indirect effect, we examined the proposed mediation paths independently to observe potential moderating effects. 
We also tested a series of models to examine the effects of between-person differences in overall substance use behavior. These models examine the likelihood of disclosure and condom use given individual differences in the following measures: A) recent alcohol use behavior (AUDIT), and B) recent drug use behavior (DAST), and C) proportion of sexual events in which participants reported using substances (Tables 4A-C).

We also conducted sensitivity analyses to compare the effects of different types of event-level substance use (e.g., PLWH used substances vs. both partners used vs. PLWH's partner used) (Tables 5A-C). We further examined moderating effects of participant and partner gender.

Within-person effects (i.e., characteristics of the sexual event) were coded dichotomously. Between-person variables based on event-level responses (e.g., individual patterns of substance use, disclosure, and condom use during sexual events) were calculated as proportions. For example, the between-person term for a participant who reported condom use on $50 \%$ of all reported sexual events was calculated as 0.5. Between-person effects based on ACASI responses (i.e., participant characteristics and patterns of behavior) were analyzed as continuous (e.g., age, AUDIT score, number of illicit substances for which participant screened positive at baseline) or categorical (e.g., gender) variables. Results for both within-person and between-person effects were reported as unstandardized betas ( $\beta$ ) along with 95\% confidence intervals (95\% CIs). Within-person effects were also reported as odds ratios (ORs) for ease of interpretation. 
To examine the degree to which observations were non-independent across clusters, intra-class correlation coefficients (ICCs) were approximated, as the categorical nature of the data prevented ICC calculation. Intraclass correlation was therefore approximated using two methods to determine the proportion of variance accounted for at level 1 (within-participant variance) and level 2 (betweenparticipant variance). ICCs were approximated first by testing the unconditional (empty) model with a linear outcome distribution and again by testing the model with a logistic outcome distribution (McCoach, 2017). The resulting two figures provide an approximate range of the proportion of variance in the dependent variable accounted for at level 2 .

Multilevel statistical analyses were conducted in MPlus version 8 (Muthén, L.K. and Muthén, B.O., 2012) . Time-invariant data collected at study entry were largely complete (less than 3.2\% missing for all variables of interest). Missing data were considered to be missing completely at random (MCAR). Therefore, full information maximum likelihood imputation was utilized to account for missing data (Little \& Rubin, 2014) . Model fit was assessed using the Akaike Information Criterion (AIC) and Bayesian Information Criterion (BIC) fit indices (Vrieze, 2012) .

Demographic statistics were analyzed in SPSS version 23 (IBM Corp, 2015) . Intraclass correlation coefficients were estimated using Hierarchical Linear Modeling Version 7 (Raudenbush, Bryk, \& Congdon, 2017) . Participant demographic data were reported as percentages and as means (M) with standard deviations (SD). Event-level sexual behavior characteristics were reported as percentages. 


\section{RESULTS}

\section{Demographic Characteristics of the Sample}

From a larger sample of 760 men and 280 women living with HIV, 251 participants reported having had anal or vaginal sex with at least one first-time sexual partner whose HIV serostatus was negative or unknown (Kalichman et al., 2016) . Participant characteristics are described in Table 1. The mean age of the sample was 42 years, and participants were predominately male (84.9\%), Black/African American (91.6\%), and lower income (62.9\% reported annual income less than $\$ 10,000)$.

\section{Sexual event characteristics}

Characteristics of sexual events are described in Table 2. During the 28-day study period, participants reported a total of 529 sexual events with first-time sexual partners whose HIV status was negative or unknown $(\mathrm{M}=2.11$ per participant). Participants reported having between one and twelve such partners during the study period, with 120 participants (47.8\%) reporting two or more such partners. The majority of sexual events (348 events; $65.7 \%$ ) occurred between two men. Male participants $(\mathrm{N}=213)$ reported 462 sexual events in total $(\mathrm{M}=2.17$ per participant); and female participants $(\mathrm{N}=38)$ reported 67 sexual events in total (M=1.76 per participant).

Participants reported using a condom during half (49.5\%) of all sexual events and using substances during $36.5 \%$ of all sexual events. Between both participants 
and their sexual partners, substance use was reported during $46.7 \%$ of events. Participants disclosed their HIV-positive serostatus to a third (32.1\%) of their firsttime, non-HIV-positive sexual partners. A non-significant trend suggested that participants who reported more first-time non-HIV-positive sexual partners were less likely to disclose their HIV serostatus during a given sexual event, despite similar patterns of event-level substance use $(\beta=-0.028, p=0.067)$.

Among participants who reported two or more first-time non-HIV-positive partners, nearly half reported inconsistent substance use (40\%) and condom use (40\%) across events. Yet the majority (72.5\%) reported a consistent pattern of serostatus disclosure or nondisclosure across sexual events. Thus, within-person variance in disclosure across events was only observed within in a small subset of participants $(\mathrm{N}=33)$; these inconsistent disclosers accounted for only a small proportion of the total sample (13.1\%). This small proportion of variance at the event level was corroborated by estimates of intra-class correlation. Estimated ICCs suggested that approximately $49 \%$ to $58 \%$ of variance in HIV serostatus disclosure was accounted for at level 2 (person-level factors). For condom use, approximately $40 \%$ to $46 \%$ of variance was estimated to be attributable to between-person factors.

\section{Multilevel Mediation Models}

To examine the relations between substance use, HIV serostatus disclosure, and condom use in a sample of PLWH and their first-time non-HIV-positive partners, we tested a series of two-level random intercept models. 


\section{Substance Use and Condom Use (Direct effect)}

As part of our primary within-person model, the event-level association between substance use and condom use was tested (Table 3). This two-level random intercept model controlled for participant characteristics including age and gender as well as the effect of sexual partner gender. Contrary to our hypothesis, results demonstrated no event-level relationship between substance use and condom use, suggesting that substance use at the time of sex was not associated with likelihood of condomless sex $(\mathrm{OR}=1.18, \beta=0.16,95 \%$ CI $[-0.50,0.82]$, $\mathrm{p}=0.630)$.

Despite the absence of a statistically significant direct effect of event-level substance use on condom use behavior, we nevertheless sought to examine the potential mediating role of HIV serostatus disclosure on the hypothesized substance use and condom use relationship. Where the mediator is hypothesized to act as a suppressor variable for the relationship between the independent and dependent variables, the direct effect need not be statistically significant to test for mediation effects (MacKinnon, Fairchild, \& Fritz, 2007). Since we expected that disclosure would suppress the hypothesized negative relationship between substance use and condom use, inconsistent mediation was conducted (Cusick, 1999; Kalichman et al., 2016) .

\section{Between-Person Models}

We also examined the relations between individuals' overall substance use behavior and their patterns of disclosure and condom use using between-person models. Results showed that self-reported heavier drinkers (measured by AUDIT) 
used condoms less regularly $(\mathrm{p}=0.05)$ (Table $4 \mathrm{~A})$. Self-reported heavier drug users (measured by DAST) also reported using condoms less frequently, although the latter trend did not meet statistical significance $(p=0.09)$ (Table 4B). When drug use was measured objectively by number of different substances used at study entry (positive urine drug screens), number of drugs used did not predict condom use. Participants who more frequently reported using substances in their first-time sexual encounters with non-HIV-positive partners were no less likely to use condoms on average (Table 4C).

\section{Substance Use and HIV Disclosure (Path A)}

To examine whether HIV serostatus disclosure mediates the relation between substance use and condom use, we first examined the relation between event-level substance use and event-level HIV serostatus disclosure (Table 3). In support of our hypothesis, results of our two-level random intercept model indicated that when either partner was using substances at the time of sex, participants were $54 \%$ less likely to disclose their HIV serostatus (OR=0.46, $\beta=-$ $0.78, \mathrm{SE}=0.38,95 \% \mathrm{CI}[-1.53,-0.05], \mathrm{p}=0.037)$. Neither AUDIT nor DAST scores were statistically significant predictors of disclosure after accounting for the eventlevel effect of substance use, and were therefore excluded from the model.

Given the significant effect of partner gender on disclosure, we also examined the relation between substance use and disclosure separately in partner gender subgroups. In events in which men had sex with non-HIV-positive men $(\mathrm{N}=175 ; 348$ events), a similar strength of effect was found, indicating a negative relationship between substance use and disclosure, although results did not remain statistically 
significant in this smaller subgroup $(\beta=-0.67, \mathrm{SE}=0.43,95 \% \mathrm{CI}[-1.51,-0.16], \mathrm{p}=$ 0.11). In women living with HIV who reported sex with non-HIV-positive men (N= 38; 67 events), an especially large effect of substance use on disclosure was observed $(\beta=-1.37, \mathrm{SE}=0.99,95 \% \mathrm{CI}[-3.30,0.57], \mathrm{p}=0.16)$. Although this effect did not remain statistically significant in this smaller subgroup, results suggested that when substances were used at the time of sex, women were $74 \%$ less likely to disclose their HIV serostatus than when neither partner used substances. Finally, during sexual events in which men living with HIV reported sex with non-HIVpositive women ( $\mathrm{N}=51 ; 100$ events), the relationship between substance use and disclosure did not approach statistical significance $(\beta=-0.27, \mathrm{SE}=1.18,95 \%$ CI [$2.59,2.05], \mathrm{p}=0.82)$.

To examine the effect of substance use specifically in the HIV-positive partners reporting sexual events (as opposed to the substance use of their sexual partners), we also examined the effect on disclosure of whether participants themselves were using substances at the time of sex (i.e., excluding the role of partner substance use) (Table 5A). In this sensitivity analysis, the effect of participant's own substance use at the time of sex did not have a statistically significant relation with likelihood of disclosure. Although this effect did not approach statistical significance, the direction of effect nevertheless suggested that when participants used substances at the time of sex, they were $33 \%$ less likely to disclose their HIV serostatus than when substances were not used $(\mathrm{OR}=0.67, \beta=-$ $0.40, \mathrm{SE}=0.35,95 \% \mathrm{CI}[-1.08,0.28], \mathrm{p}=0.25)$. We also examined whether events in which both partners were using substances were associated with different 
disclosure likelihood than events in which neither or only one partner used substances (Table 5B). No statistically significant relationship was found. Finally, we also compared the likelihood of disclosure when the first-time non-HIV-positive sexual partner of the participant used substances or not (Table 5C). Sexual partner substance use was not statistically significantly associated with disclosure, although the direction of the non-significant effect suggested that PLWH may be less likely to disclose their serostatus when their first-time non-HIV-positive partners are using substances $(\mathrm{OR}=0.70 \beta=-0.36, \mathrm{SE}=0.37,95 \% \mathrm{CI}[-1.07,0.36], \mathrm{p}=0.33)$.

Between-person models

Heavier drinkers and drug users by self-report were less likely to disclose their HIV status to sexual partners on average, although number of positive drug screens did not predict disclosure (Tables 4A \& 4B). In participants who more frequently used substances during sexual encounters, these participants were less likely to disclose their HIV serostatus (Table 4C).

\section{HIV Disclosure and Condom Use (Path B)}

In our primary analysis, we also examined the event-level relation between HIV serostatus disclosure and condom use (Table 3). Contrary to hypotheses, in participants who used condoms inconsistently $(\mathrm{N}=48)$, participants were no less likely to report condom use during sexual events in which they disclosed their HIV status $(O R=1.01, \beta=0.01, \mathrm{SE}=95 \% \mathrm{CI}[-0.68,0.69], \mathrm{p}=0.99)$. This finding stands in contrast to our hypothesis that disclosure would increase the likelihood of condom use. 
We next examined the separate within-person and between-person effects of disclosure on condom use together in one model (Table 6). Despite the counterintuitive within-person effect (in this model, event-level disclosure was associated with decreased likelihood of condom use among inconsistent condom users), the between-person result indicated that participants who consistently used condoms $(\mathrm{N}=106)$ were more likely to have disclosed their HIV status than participants who consistently engaged in condomless sex $(N=97)(\beta=1.67, \mathrm{SE}=$ 0.62, 95\% CI $[0.65,2.69], \mathrm{p}<0.01)$. Thus, the relationship between disclosure and condom use appears to differ between consistent and inconsistent disclosers.

Although event-level substance use was not associated with greater condom use in the total sample, we sought to examine whether substance use may exert a different effect on condom use behavior in sexual events in which disclosure had occurred vs. those in which disclosure had not occurred. Our subgroup analyses showed that in either case, substance use at the time of sex was not significantly associated with condom use behavior (p's > 0.05). Thus, event-level substance use does not appear to account for condom non-use following disclosure.

To better understand this counterintuitive finding, we performed exploratory follow-up analyses to examine participant characteristics associated with condom non-use during sexual events in which HIV disclosure had occurred. We included all participants who reported disclosing their HIV status to at least one non-HIV-positive sex partner. We then compared the characteristics of those who always used condoms during such events to those who did not always use condoms in spite of disclosure. Independent-sample t-tests were used for continuous 
variables and $\mathrm{X}^{2}$ analyses for categorical variables. Comparisons were made at the person level. Individuals who reported condomless sex following disclosure were found to have fewer common HIV-related symptoms $(\mathrm{t}(2,90)=2.14, \mathrm{p}=0.035)$, poorer safe sex behavioral skills $(\mathrm{t}(2,90)=2.31, \mathrm{p}=0.007)$, and better social support $(t(2,89)=-2.73, p=0.008)$ than those who always reported condom-protected sex following disclosure. Marginal trends suggested that those who engaged in condomless sex following disclosure perceived less HIV transmission risk associated with condomless sex $(t(2,89)=1.81, p=0.075)$, and reported greater drug use (DAST) $(t(2,74.4)=-1.76, p=0.083)$. No statistically significant differences were observed for age, gender, years since HIV diagnosis, AUDIT score, ARV medication adherence, CD4 count, HIV viral load, or beliefs that treatment reduces HIV transmission risk. Those who engaged in condomless sex following disclosure were no more likely to have concurrent STIs, to have a positive drug screen, or to be prescribed antiretroviral treatment.

\section{Tests of Indirect Effects}

A test of the indirect effect in our primary model did not find a mediating effect of disclosure on the event-level relationship between substance use and condom use ( $\beta=-0.00, \mathrm{SE}=0.28,95 \% \mathrm{CI}[-0.55,0.54], \mathrm{p}=0.99)$ (Table 3). While event-level substance use was associated with decreased likelihood of HIV serostatus disclosure (Path A), nondisclosure was not associated with condom nonuse among inconsistent condom users (Path B).

In our models of the between-person effects of substance use on condom use behavior (i.e., models examining AUDIT scores, DAST scores, number of positive 
SUBSTANCE USE, HIV DISCLOSURE, \& CONDOM USE

drug screens, and proportion of sexual events involving substances), we similarly

found no statistically significant mediation effects, owing to a lack of a relationship between disclosure and condom use (Tables 4A-4C). 


\section{DISCUSSION}

To prevent transmission of HIV, an understanding of the role of substance use in sexual risk behavior is of critical importance. Results of our study indicate that substance use at the time of sex reduces the likelihood of PLWH informing casual non-HIV-positive sexual partners of their HIV-positive status. Given that PLWH who engage in condomless nondisclosed sex are more likely to demonstrate several indicators of increased infectiousness (i.e., poorer ARV adherence, more recent STI infections, and higher HIV viral load), this finding is especially consequential for informing HIV prevention efforts (Kalichman et al., 2016) .

The strength of the relationship between substance use and disclosure appeared to differ substantially depending on the genders of PLWH and their sexual partners. While smaller sample sizes across these subgroups precludes definitive conclusions, our results suggest that the negative relationship between substance use and disclosure appears to be largest among women living with HIV, and smallest among men living with HIV when their non-HIV-positive partners are women. These results are consistent with prior research indicating that women-particularly those with a history of sexual victimization-may be more likely to abdicate sexual safety decision-making while intoxicated due to anticipation of negative partner reactions (George et al., 2016; Stappenbeck et al., 2016) .

While we anticipated that HIV disclosure would facilitate taking greater preventative health precautions, we were surprised to find that disclosure was not associated with a greater likelihood of using a condom among those who reported 
inconsistent condom use. This unanticipated finding suggests that the potential risk reduction benefit of increasing HIV disclosure in casual sexual encounters may be overestimated. While surprising in light of prevailing sociocognitive theories of behavior, our finding adds to a growing body of literature demonstrating mixed support for an effect of HIV disclosure on condom use behavior (Simoni \& Pantalone, 2004; Sullivan, 2005) .

A number of factors may help to explain the counterintuitive finding that disclosure of HIV status to non-HIV-positive partners did not appear to increase the frequency of condom use in casual encounters. Previous qualitative research has suggested that sexually risky men and women with HIV who perceive themselves to be responsible for protecting their partners may use risk reduction strategies such as condom use to avoid the socially risky act of disclosing their HIV status (Bird \& Voisin, 2011; Cusick, 1999) . However, efforts to avoid disclosure may not always result in increased frequency of condom use. In contrast, some PLWH have reported that when they wish to conceal their HIV status, they may avoid using a condom out of fear that doing so would betray their HIV-positive status (Cusick, 1999) . Another critical consideration is that condom use likely provides an incomplete measure of sexual risk reduction efforts. It is therefore possible that the lack of a relationship between disclosure and condom use may be attributable to sexual harm reduction methods not captured in the present study (Parsons, Schrimshaw, Wolitski et al., 2005) . Risk reduction strategies such as strategic positioning, serosorting, and withdrawal before ejaculation may be alternative methods by which PLWH and their partners attempt to decrease HIV transmission risk (Cruess et al., 2017; 
Dangerfield, Smith, Williams, Unger, \& Bluthenthal, 2017; Eaton, Kalichman, O'Connell, \& Karchner, 2009; McFarland et al., 2012; Vallabhaneni et al., 2012) . Although not captured in the present study, reliance upon such alternative risk reduction tactics could help to explain high rates of condomless sex between serodiscordant partners even following disclosure. Some potential partners of PLWH may also abstain from anal or vaginal sex altogether following their partner's HIV disclosure, rather than using condoms.

Our study also contributes to a conflicting body of evidence concerning the acute effects of substance use on condom use decision-making. Consistent with prior literature, our between-person measures of substance use suggested that heavier alcohol drinkers were those most likely to engage in condom-unprotected sex (Koblin et al., 2006b; Mayer et al., 2014; Scott-Sheldon et al., 2013) . Yet our test did not support an event-level relationship between substance use and condom use, suggesting that substance use at the time of sex did not increase sexual risk-taking after accounting for these between-person characteristic use patterns. Although labbased research has indicated that acute alcohol intoxication is associated with increased willingness to engage in condomless sex, results from this sample corroborate previous event-level analyses that have failed to find an immediate relationship between substance use and sexual risk behavior (Davis et al., 2009; George et al., 2009; Gillmore et al., 2002; Reilly \& Woo, 2001) . This evidence may point to the primacy of person-level factors such sensation seeking in explaining the relationship between substance use and sexual risk behavior. Alternatively, they 
SUBSTANCE USE, HIV DISCLOSURE, \& CONDOM USE

may indicate a lack of sensitivity in the current study's assessment of substance use behavior.

In spite of the design strengths of the present study, several notable limitations warrant discussion. As is true of the majority of sexual behavior research, our study was limited by its reliance on self-report. With regard to measurement of socially sensitive behaviors such as condom use, HIV disclosure, and substance use, some underreporting is likely. Previous examinations of alcohol use self-report have demonstrated limited test-retest reliability (Johnson, Pratt, Neal, \& Fisher, 2010) . Sexual behavior data is also vulnerable to underreporting bias, with inaccuracy of self-report during retrospective recall found to be greatest among those at highest transmission risk, such as those who report more casual partners and those with lower education levels (Jaccard et al., 2004) . To minimize the possibility of underreporting bias, our study utilized state-of-the-art daily electronic data collection methodology. This method has demonstrated reliable measurement of socially sensitive behaviors in previous research, yet such methods cannot entirely remove the possibility of underreporting (Bernhardt et al., 2009; McAuliffe et al., 2010) .

A second limitation of our study is the lack of specific data characterizing event-level substance use. To reduce study burden, participants answered one item regarding substance use during each sexual event (i.e., specifying whether both the participant and/or their sexual partner had used substances). While this brief question format provided participants with a less demanding daily burden, greater specificity concerning the variety of substance(s) used would have offered valuable 
data concerning differential substance use effects. As substances vary in their psychoactive effects and associated behavioral expectancies, the present study's lack of granularity concerning the types of substances used may have obscured some relationships between substance use and associated sexual behaviors. Further, as prior event-level studies of alcohol use have detected relationships between number of drinks consumed and daily sexual risk behavior, predictive value may also have been missed by failing to capture impairment (Barta et al., 2008)

Finally, our study was limited in its scope. Much event-level research does not account for the potential importance of contextual factors such as meeting venue for HIV transmission risk behavior (Grov, 2012; Horvath, Bowen, \& Williams, 2006; Jones-Webb et al., 2013) . While some research has indicated that sexual risk behavior appears to be more contingent on personal psychosocial factors than on meeting venue features, risk behavior norms nevertheless appear to differ significantly across venue types in MSM (Grov, Parsons, \& Bimbi, 2007; Grov, 2012) .

Despite these limitations, this study utilized sensitive and state-of-the-art electronic diary data collection, and applied a multilevel modeling analytic approach that provided significant methodological advantages. Analytic methods that fail to account for non-independence of observations when data is clustered increase the likelihood of Type I error (Musca et al., 2011) . Additionally, attempts to examine within-person phenomena using between-person measures are vulnerable to a variety of potential confounders that may bias findings (Robinson, 1950) . In contrast, the present study utilized a robust and conservative analytic approach to 
isolate the event-level factors that influence sexual risk decision-making. In the present study, all estimates of intraclass correlation indicated that a substantial proportion of variance in the dependent variables was accounted for by level 2 factors. These tests provide another strong statistical justification for the necessity of a multilevel analytic approach rather than ignoring participant variance in analysis of specific events.

\section{Future directions}

The present study highlights the complex and multifactorial interplay of personal and situational factors that influence HIV transmission risk behavior in PLWH. Future research should continue to utilize event-level methodology to better understand the causal pathways by which substance use may influence sexual risk behavior. Greater specificity in measurement substance use type and impairment is needed to better understand the impact of substance use on health behavior decision-making.

Irrespective of the immediate effects that substance use may exert on sexual health decision-making, substance use is strongly linked to HIV transmission risk through a number of indirect pathways. Problematic drug and alcohol use has been consistently linked with lack of successful engagement in HIV testing and care among PLWH, which increases the risk of transmission of HIV due to unsuppressed HIV viral load, in addition to increasing HIV disease severity (Cohen, 1998; Lucas, Cheever, Chaisson, \& Moore, 2001; Parsons, Kowalczyk, Botsko, Tomassilli, \& Golub, 2013; Quinn et al., 2000; Vagenas et al., 2015; Williams et al., 2018) . Personal factors such as sexual compulsivity, sensation seeking, and belonging to high-risk 
sexual networks may also account for much of the association between substance use and HIV transmission risk (Day et al., 2015; Hernandez-Romieu et al., 2015; Kalichman, Cain, Zweben, \& Swain, 2003; Newcomb, Clerkin, \& Mustanski, 2011; Norris et al., 2009) . Thus, future studies should strive to measure and examine relevant risk-related beliefs as well as personality and demographic factors that may contribute to increased HIV transmission risk behavior in substance-using PLWH and their partners.

In light of the disproportionately high risk of HIV transmission among people who use substances, interventions that address sexual risk reduction in this population must address the complex etiology of HIV risk behaviors in this population. Successful behavioral change interventions should target multiple behaviors concurrently (Coates, Richter, \& Caceres, 2008) . Promotion of partner HIV disclosure may be a valuable adjunct to sexual risk reduction strategies, yet alone may be insufficient for reliably improving sexual health behavior. Addressing substance use disorders, barriers to medication adherence, concurrent STIs, trauma, stigma, and mental health concerns, are all critical supplements for successful behavioral prevention interventions in PLWH (Burnham et al., 2016; Kalichman et al., 2016; Stappenbeck et al., 2016; Williams et al., 2018) . For instance, methadone maintenance treatment for opioid drug using PLWH may help to reduce sexual risk behavior by reducing reliance on transactional sex (Karki, Shrestha, Huedo-Medina, \& Copenhaver, 2016) . Promotion of sexual risk reduction in the context of more recreational forms of alcohol or other drug use is also warranted. 
Given the multiple means by which people may attempt to reduce sexual transmission risk, future research should examine use of alternative risk reduction strategies beyond condom use. Understanding use of perceived sexual harm reduction practices such as strategic sexual positioning may shed greater light on the decision-making frameworks utilized by PLWH and their partners (Parsons et al., 2005) . Similarly, greater understanding of evolving HIV risk perceptions and beliefs (e.g., treatment-as-prevention beliefs) may help to understand sexual risk behaviors (Kalichman et al., 2017) . Considering the fundamentally interpersonal nature of sexual risk behaviors, dyadic analysis may also help to understand the interplay of beliefs, behaviors, risk perceptions, skills, and anticipated partner reactions involved in negotiating sexual health decisions between partners.

Researchers should also examine the role of emerging pharmaceutical alternatives such as Pre-Exposure Prophylaxis (PrEP) in sexual health decisionmaking. Such biomedical alternatives carry tremendous potential to reduce the consequences associated with sexual risk behaviors made in the "heat of the moment" among partners of PLWH. Nevertheless, potential risk compensation behavior such as condom non-use in PrEP user should be scrutinized, given the increased risk of HIV transmission associated with concurrent STI infection (Cohen, 1998; Cohen, 2012) . Uptake of PrEP remains sporadic, and rates of PrEP use remain particularly low among those at greatest risk for acquiring HIV (Eaton, Driffin, Bauermeister, Smith, \& Conway-Washington, 2015; Mimiaga, Closson, Kothary, \& Mitty, 2014). Thus, sexual partners of PLWH may be especially unlikely to obtain 
SUBSTANCE USE, HIV DISCLOSURE, \& CONDOM USE

the benefits of PrEP, further emphasizing the importance of effective behavioral prevention interventions in PLWH.

\section{Conclusions}

This study is the first to apply multilevel modeling methodology to examine the immediate determinants of HIV serostatus disclosure in PLWH's first-time sexual encounters with non-HIV-positive partners. Our findings offer an important contribution to understanding the role of substance use in HIV transmission risk behavior. We found that use of substances at the time of sex appears to be associated with lower likelihood of disclosing one's HIV-positive status to casual sex partners. Yet while nondisclosure of HIV status was more frequent when substances were used at the time of sex, this nondisclosure was not associated with lower likelihood of condom use in those who used condoms inconsistently. Our study also contributes to the mixed literature concerning the relationship between substance use and condom use. We found that heavier alcohol users were more likely to engage in condomless sex, yet substance use at the time of sex was not associated with a greater likelihood of condomless sex in inconsistent condom users. Our findings provide insight regarding the socially fraught process of sexual health decision-making in PLWH, and add nuance regarding the complex and multiple relations between substance use and sexual risk behavior. 


\section{REFERENCES}

Ajzen, I. (2002). Perceived behavioral control, self-efficacy, locus of control, and the theory of planned behavior. Journal of Applied Social Psychology, 32(4), 665-683.

Albarracin, D., Johnson, B. T., Fishbein, M., \& Muellerleile, P. A. (2001). Theories of reasoned action and planned behavior as models of condom use: A metaanalysis. Psychological Bulletin, 127(1), 142.

Barta, W. D., Portnoy, D. B., Kiene, S. M., Tennen, H., Abu-Hasaballah, K. S., \& Ferrer, R. (2008). A daily process investigation of alcohol-involved sexual risk behavior among economically disadvantaged problem drinkers living with HIV/AIDS. AIDS and Behavior, 12(5), 729-740.

Baugher, A. R., Beer, L., Fagan, J. L., Mattson, C. L., Freedman, M., Skarbinski, J., \& Shouse, R. L. (2017). Prevalence of internalized HIV-related stigma among HIVinfected adults in care, united states, 2011-2013. AIDS and Behavior, 21(9), 2600-2608.

Bernhardt, J. M., Usdan, S., Mays, D., Martin, R., Cremeens, J., \& Arriola, K. J. (2009). Alcohol assessment among college students using wireless mobile technology. Journal of Studies on Alcohol and Drugs, 70(5), 771-775.

Bird, J. D., Eversman, M., \& Voisin, D. R. (2017). “You just can't trust everybody”: The impact of sexual risk, partner type and perceived partner trustworthiness on HIV-status disclosure decisions among HIV-positive black gay and bisexual men. Culture, Health \& Sexuality, 19(8), 829-843. 
Bird, J. D., \& Voisin, D. R. (2011). A conceptual model of HIV disclosure in casual sexual encounters among men who have sex with men. Journal of Health Psychology, 16(2), 365-373.

Bird, J. D., \& Voisin, D. R. (2013). "You're an open target to be abused": A qualitative study of stigma and HIV self-disclosure among black men who have sex with men. American Journal of Public Health, 103(12), 2193-2199.

Bourne, A., \& Weatherburn, P. (2017). Substance use among men who have sex with men: Patterns, motivations, impacts and intervention development need. Sexually Transmitted Infections, doi:sextrans-2016-052674 [pii]

Brown, M. J., Serovich, J. M., \& Kimberly, J. A. (2016). Depressive symptoms, substance use and partner violence victimization associated with HIV disclosure among men who have sex with men. AIDS and Behavior, 20(1), 184192.

Broyd, S. J., van Hell, H. H., Beale, C., Yucel, M., \& Solowij, N. (2016). Acute and chronic effects of cannabinoids on human cognition-A systematic review. Biological Psychiatry, 79(7), 557-567. doi:10.1016/j.biopsych.2015.12.002 [doi]

Bruce, D., Kahana, S., Harper, G. W., Fernandez, M. I., \& ATN. (2013). Alcohol use predicts sexual risk behavior with HIV-negative or partners of unknown status among young HIV-positive men who have sex with men. AIDS Care, 25(5), 559565. doi:10.1080/09540121.2012.720363 [doi]

Bryan, A. D., Schmiege, S. J., \& Magnan, R. E. (2012). Marijuana use and risky sexual behavior among high-risk adolescents: Trajectories, risk factors, and event-level 
SUBSTANCE USE, HIV DISCLOSURE, \& CONDOM USE

relationships. Developmental Psychology, 48(5), 1429-1442.

doi:10.1037/a0027547 [doi]

Burnham, K. E., Cruess, D. G., Kalichman, M. O., Grebler, T., Cherry, C., \& Kalichman, S. C. (2016). Trauma symptoms, internalized stigma, social support, and sexual risk behavior among HIV-positive gay and bisexual MSM who have sought sex partners online. AIDS Care, 28(3), 347-353.

Card, K. G., Lachowsky, N. J., Cui, Z., Sereda, P., Rich, A., Jollimore, J., . . Montaner, J. (2017). Seroadaptive strategies of gay \& bisexual men (GBM) with the highest quartile number of sexual partners in vancouver, canada. AIDS and Behavior, 21(5), 1452-1466.

Carver, C. S., Scheier, M. F., \& Weintraub, J. K. (1989). Assessing coping strategies: A theoretically based approach. Journal of Personality and Social Psychology, 56(2), 267.

Center for Disease Control and Prevention. (2016). HIV surveillance report, 2015. ( No. vol. 27). Retrieved from http://www.cdc.gov/hiv/library/reports/hivsurveillance.html

Center for Disease Control and Prevention. (2017). Trends in U.S. HIV diagnoses, 2005-2014. Retrieved from https://www.cdc.gov/nchhstp/newsroom/2015/nhpc.html

Chiasson, M. A., Shaw, F. S., Humberstone, M., Hirshfield, S., \& Hartel, D. (2009). Increased HIV disclosure three months after an online video intervention for men who have sex with men (MSM). AIDS Care, 21(9), 1081-1089. 
Ciccarone, D. H., Kanouse, D. E., Collins, R. L., Miu, A., Chen, J. L., Morton, S. C., \& Stall, R. (2003). Sex without disclosure of positive HIV serostatus in a US probability sample of persons receiving medical care for HIV infection. American Journal of Public Health, 93(6), 949-954.

Coates, T. J., Richter, L., \& Caceres, C. (2008). Behavioural strategies to reduce HIV transmission: How to make them work better. Lancet (London, England), 372(9639), 669-684. doi:10.1016/S0140-6736(08)60886-7 [doi]

Cocco, K. M., \& Carey, K. B. (1998). Psychometric properties of the drug abuse screening test in psychiatric outpatients. Psychological Assessment, 10(4), 408.

Cohen, M. S. (1998). Sexually transmitted diseases enhance HIV transmission: No longer a hypothesis. Lancet (London, England), 351 Suppl 3, 5-7.

Cohen, M. S. (2012). Classical sexually transmitted diseases drive the spread of HIV1: Back to the future. The Journal of Infectious Diseases, 206(1), 1-2. doi:10.1093/infdis/jis303 [doi]

Colfax, G., Vittinghoff, E., Husnik, M. J., McKirnan, D., Buchbinder, S., Koblin, B., ... Mayer, K. (2004). Substance use and sexual risk: A participant-and episodelevel analysis among a cohort of men who have sex with men. American Journal of Epidemiology, 159(10), 1002-1012.

Compas, B. E., Connor-Smith, J. K., Saltzman, H., Thomsen, A. H., \& Wadsworth, M. E. (2001). Coping with stress during childhood and adolescence: Problems, progress, and potential in theory and research. Psychological Bulletin, 127(1), 87. 
Conserve, D. F., Groves, A. K., \& Maman, S. (2015). Effectiveness of interventions promoting HIV serostatus disclosure to sexual partners: A systematic review. AIDS and Behavior, 19(10), 1763-1772.

Cooper, M. L. (2002). Alcohol use and risky sexual behavior among college students and youth: Evaluating the evidence. Journal of Studies on Alcohol, Supplement, (14), 101-117.

Crawford, J., Rodden, P., Kippax, S., \& Van de Ven, P. (2001). Negotiated safety and other agreements between men in relationships: Risk practice redefined. International Journal of STD \& AIDS, 12(3), 164-170.

Crowe, L. C., \& George, W. H. (1989). Alcohol and human sexuality: Review and integration. Psychological Bulletin, 105(3), 374.

Cruess, D. G., Burnham, K. E., Finitsis, D. J., Goshe, B. M., Strainge, L., Kalichman, M., . . . Kalichman, S. C. (2017). A randomized clinical trial of a brief internet-based group intervention to reduce sexual transmission risk behavior among HIVpositive gay and bisexual men. Annals of Behavioral Medicine,

Cusick, L. (1999). The process of disclosing positive HIV status: Findings from qualitative research. Culture, Health \& Sexuality, 1(1), 3-18.

Dangerfield, D. T., Smith, L. R., Williams, J., Unger, J., \& Bluthenthal, R. (2017). Sexual positioning among men who have sex with men: A narrative review. Archives of Sexual Behavior, 46(4), 869-884.

Davis, K. C., George, W. H., Norris, J., Schacht, R. L., Stoner, S. A., Hendershot, C. S., \& Kajumulo, K. F. (2009). Effects of alcohol and blood alcohol concentration limb 
SUBSTANCE USE, HIV DISCLOSURE, \& CONDOM USE

on sexual risk-taking intentions. Journal of Studies on Alcohol and Drugs, 70(4), 499-507.

Davis, K. C., Jacques-Tiura, A. J., Stappenbeck, C. A., Danube, C. L., Morrison, D. M., Norris, J., \& George, W. H. (2016). Men's condom use resistance: Alcohol effects on theory of planned behavior constructs. Health Psychology, 35(2), 178.

Day, A. M., Kahler, C. W., Ahern, D. C., \& Clark, U. S. (2015). Executive functioning in alcohol use studies: A brief review of findings and challenges in assessment. Current Drug Abuse Reviews, 8(1), 26-40. doi:CDAR-EPUB-66580 [pii]

Eaton, L. A., Driffin, D. D., Bauermeister, J., Smith, H., \& Conway-Washington, C. (2015). Minimal awareness and stalled uptake of pre-exposure prophylaxis (PrEP) among at risk, HIV-negative, black men who have sex with men. AIDS Patient Care and STDs, 29(8), 423-429.

Eaton, L. A., Kalichman, S. C., O'Connell, D. A., \& Karchner, W. D. (2009). A strategy for selecting sexual partners believed to pose little/no risks for HIV: Serosorting and its implications for HIV transmission. AIDS Care, 21(10), 1279-1288.

Elwood, W. N., Greene, K., \& Carter, K. K. (2003). Gentlemen don't speak:

Communication norms and condom use in bathhouses. Journal of Applied Communication Research, 31(4), 277-297.

Field, M., Wiers, R. W., Christiansen, P., Fillmore, M. T., \& Verster, J. C. (2010). Acute alcohol effects on inhibitory control and implicit cognition: Implications for loss of control over drinking. Alcoholism: Clinical and Experimental Research, 34(8), 1346-1352. 
Fisher, J. D., \& Fisher, W. A. (1992). Changing AIDS-risk behavior. Psychological Bulletin, 111(3), 455.

Folkman, S., Chesney, M. A., Pollack, L., \& Phillips, C. (1992). Stress, coping, and highrisk sexual behavior. Health Psychology, 11(4), 218.

Galletly, C. L., \& Dickson-Gomez, J. (2009). HIV seropositive status disclosure to prospective sex partners and criminal laws that require it: Perspectives of persons living with HIV. International Journal of STD \& AIDS, 20(9), 613-618.

George, W. H., Davis, K. C., Masters, N. T., Kajumulo, K. F., Stappenbeck, C. A., Norris, J., . . . Staples, J. M. (2016). Partner pressure, victimization history, and alcohol: Women's condom-decision abdication mediated by mood and anticipated negative partner reaction. AIDS and Behavior, 20(1), 134-146.

George, W. H., Davis, K. C., Norris, J., Heiman, J. R., Stoner, S. A., Schacht, R. L., . . Kajumulo, K. F. (2009). Indirect effects of acute alcohol intoxication on sexual risk-taking: The roles of subjective and physiological sexual arousal. Archives of Sexual Behavior, 38(4), 498-513.

Gielen, A. C., McDonnell, K. A., Burke, J. G., \& O'campo, P. (2000). Women's lives after an HIV-positive diagnosis: Disclosure and violence. Maternal and Child Health Journal, 4(2), 111-120.

Gillmore, M. R., Morrison, D. M., Leigh, B. C., Hoppe, M. J., Gaylord, J., \& Rainey, D. T. (2002). Does "high= high risk"? an event-based analysis of the relationship between substance use and unprotected anal sex among gay and bisexual men. AIDS and Behavior, 6(4), 361-370. 
Gribble, J. N., Miller, H. G., Cooley, P. C., Catania, J. A., Pollack, L., \& Turner, C. F. (2000). The impact of T-ACASI interviewing on reported drug use among men who have sex with men. Substance use \& Misuse, 35(6-8), 869-890.

Grov, C. (2012). HIV risk and substance use in men who have sex with men surveyed in bathhouses, bars/clubs, and on craigslist. org: Venue of recruitment matters. AIDS and Behavior, 16(4), 807-817.

Grov, C., Parsons, J. T., \& Bimbi, D. S. (2007). Sexual risk behavior and venues for meeting sex partners: An intercept survey of gay and bisexual men in LA and NYC. AIDS and Behavior, 11(6), 915-926.

Hann, D., Winter, K., \& Jacobsen, P. (1999). Measurement of depressive symptoms in cancer patients: Evaluation of the center for epidemiological studies depression scale (CES-D). Journal of Psychosomatic Research, 46(5), 437-443. doi:S0022399999000045 [pii]

Hensel, D. J., Stupiansky, N. W., Orr, D. P., \& Fortenberry, J. D. (2011). Event-level marijuana use, alcohol use, and condom use among adolescent women. Sexually Transmitted Diseases, 38(3), 239-243. doi:10.1097/OLQ.0b013e3181f422ce [doi]

Hernandez-Romieu, A. C., Sullivan, P. S., Rothenberg, R., Grey, J., Luisi, N., Kelley, C. F., \& Rosenberg, E. S. (2015). Heterogeneity of HIV prevalence among the sexual networks of black and white men who have sex with men in atlanta:

Illuminating a mechanism for increased HIV risk for young black men who have sex with men. Sexually Transmitted Diseases, 42(9), 505-512.

doi:10.1097/OLQ.0000000000000332 [doi] 
Horvath, K. J., Bowen, A. M., \& Williams, M. L. (2006). Virtual and physical venues as contexts for HIV risk among rural men who have sex with men. Health Psychology, 25(2), 237.

IBM Corp. (2015). IBM SPSS statistics for windows, version 23.0. armonk, NY: IBM corp.

Jaccard, J., McDonald, R., Wan, C. K., Guilamo-Ramos, V., Dittus, P., \& Quinlan, S. (2004). Recalling sexual partners: The accuracy of self-reports. Journal of Health Psychology, 9(6), 699-712.

Johnson, M. E., Pratt, D. K., Neal, D. B., \& Fisher, D. G. (2010). Drug users' test-retest reliability of self-reported alcohol use on the risk behavior assessment. Substance use \& Misuse, 45(6), 925-935.

Jones-Webb, R., Smolenski, D., Brady, S., Wilkerson, M., \& Rosser, B. S. (2013).

Drinking settings, alcohol consumption, and sexual risk behavior among gay men. Addictive Behaviors, 38(3), 1824-1830.

Kahler, C. W., Wray, T. B., Pantalone, D. W., Kruis, R. D., Mastroleo, N. R., Monti, P. M., \& Mayer, K. H. (2015). Daily associations between alcohol use and unprotected anal sex among heavy drinking HIV-positive men who have sex with men. AIDS and Behavior, 19(3), 422-430. doi:10.1007/s10461-014-0896-7 [doi]

Kalichman, S. C., Kalichman, M. O., Cherry, C., \& Grebler, T. (2016). HIV disclosure and transmission risks to sex partners among HIV-positive men. AIDS Patient Care and STDs, 30(5), 221-228.

Kalichman, S. C., \& Nachimson, D. (1999). Self-efficacy and disclosure of HIV-positive serostatus to sex partners. Health Psychology, 18(3), 281. 
Kalichman, S. C., Price, D., Eaton, L. A., Burnham, K., Sullivan, M., Finneran, S., . . . Allen, A. (2017). Diminishing perceived threat of AIDS and increasing sexual risks of HIV among men who have sex with men, 1997-2015. Archives of Sexual Behavior, 46(4), 895-902.

Kalichman, S. C., Simbayi, L. C., Cain, D., \& Jooste, S. (2007). Alcohol expectancies and risky drinking among men and women at high-risk for HIV infection in cape town south africa. Addictive Behaviors, 32(10), 2304-2310.

Kalichman, S. C., Cain, D., Zweben, A., \& Swain, G. (2003). Sensation seeking, alcohol use and sexual risk behaviors among men receiving services at a clinic for sexually transmitted infections. Journal of Studies on Alcohol, 64(4), 564-569.

Kalichman, S. C., Cherry, C., Kalichman, M. O., Washington, C., Grebler, T., Hoyt, G., ... Welles, B. (2016). Sexual behaviors and transmission risks among people living with HIV: Beliefs, perceptions, and challenges to using treatments as prevention. Archives of Sexual Behavior, 45(6), 1421-1430. doi:10.1007/s10508-015-0559-4 [doi]

Kalichman, S. C., Rompa, D., Cage, M., DiFonzo, K., Simpson, D., Austin, J., ... Graham, J. (2001). Effectiveness of an intervention to reduce HIV transmission risks in HIV-positive people. American Journal of Preventive Medicine, 21(2), 84-92. doi:S0749-3797(01)00324-5 [pii]

Karki, P., Shrestha, R., Huedo-Medina, T. B., \& Copenhaver, M. (2016). The impact of methadone maintenance treatment on HIV risk behaviors among high-risk injection drug users: A systematic review. Evidence-Based Medicine \& Public Health, 2 doi:e1229 [pii] 
Khan, M. R., Berger, A., Hemberg, J., O'Neill, A., Dyer, T. P., \& Smyrk, K. (2013). Noninjection and injection drug use and STI/HIV risk in the united states: The degree to which sexual risk behaviors versus sex with an STI-infected partner account for infection transmission among drug users. AIDS and Behavior, 17(3), 1185-1194. doi:10.1007/s10461-012-0276-0 [doi]

Koblin, B. A., Husnik, M. J., Colfax, G., Huang, Y., Madison, M., Mayer, K., . . . Buchbinder, S. (2006a). Risk factors for HIV infection among men who have sex with men. AIDS (London, England), 20(5), 731-739. doi:10.1097/01.aids.0000216374.61442.55 [doi]

Koblin, B. A., Husnik, M. J., Colfax, G., Huang, Y., Madison, M., Mayer, K., . . . Buchbinder, S. (2006b). Risk factors for HIV infection among men who have sex with men. AIDS (London, England), 20(5), 731-739. doi:10.1097/01.aids.0000216374.61442.55 [doi]

Lehman, J. S., Carr, M. H., Nichol, A. J., Ruisanchez, A., Knight, D. W., Langford, A. E., ... Mermin, J. H. (2014). Prevalence and public health implications of state laws that criminalize potential HIV exposure in the united states. AIDS and Behavior, 18(6), 997-1006.

Little, R. J., \& Rubin, D. B. (2014). Statistical analysis with missing data John Wiley \& Sons.

Lucas, G. M., Cheever, L. W., Chaisson, R. E., \& Moore, R. D. (2001). Detrimental effects of continued illicit drug use on the treatment of HIV-1 infection. Journal of Acquired Immune Deficiency Syndromes (1999), 27(3), 251-259. 
SUBSTANCE USE, HIV DISCLOSURE, \& CONDOM USE

MacAndrew, C., \& Edgerton, R. B. (1969). Drunken comportment: A social explanation.

MacKinnon, D. P., Fairchild, A. J., \& Fritz, M. S. (2007). Mediation analysis. Annu.Rev.Psychol., 58, 593-614.

Mansergh, G., Shouse, R. L., Marks, G., Guzman, R., Rader, M., Buchbinder, S., \& Colfax, G. N. (2006). Methamphetamine and sildenafil (viagra) use are linked to unprotected receptive and insertive anal sex, respectively, in a sample of men who have sex with men. Sexually Transmitted Infections, 82(2), 131-134. doi:82/2/131 [pii]

Marks, G., \& Crepaz, N. (2001). HIV-positive men's sexual practices in the context of self-disclosure of HIV status. JAIDS Journal of Acquired Immune Deficiency Syndromes, 27(1), 79-85.

Martin, J. I., Pryce, J. G., \& Leeper, J. D. (2005). Avoidance coping and HIV risk behavior among gay men. Health \& Social Work, 30(3), 193-201.

Mayer, K. H., Colfax, G., \& Guzman, R. (2006). Club drugs and HIV infection: A review. Clinical Infectious Diseases, 42(10), 1463-1469.

Mayer, K. H., Skeer, M. R., O'Cleirigh, C., Goshe, B. M., \& Safren, S. A. (2014). Factors associated with amplified HIV transmission behavior among american men who have sex with men engaged in care: Implications for clinical providers. Annals of Behavioral Medicine : A Publication of the Society of Behavioral Medicine, 47(2), 165-171. doi:10.1007/s12160-013-9527-1 [doi] 
McAuliffe, T. L., DiFranceisco, W., \& Reed, B. R. (2010). Low numeracy predicts reduced accuracy of retrospective reports of frequency of sexual behavior. AIDS and Behavior, 14(6), 1320-1329.

McCoach, D. (2017). Personal interview

McFarland, W., Chen, Y., Nguyen, B., Grasso, M., Levine, D., Stall, R., ... Raymond, H. F. (2012). Behavior, intention or chance? A longitudinal study of HIV seroadaptive behaviors, abstinence and condom use. AIDS and Behavior, 16(1), 121-131.

McKirnan, D. J., Ostrow, D. G., \& Hope, B. (1996). Sex, drugs and escape: A psychological model of HIV-risk sexual behaviours. AIDS Care, 8(6), 655-670.

McKirnan, D. J., Vanable, P. A., Ostrow, D. G., \& Hope, B. (2001). Expectancies of sexual "escape" and sexual risk among drug-and alcohol-involved gay and bisexual men. Journal of Substance Abuse, 13(1-2), 137-154.

Mimiaga, M. J., Closson, E. F., Kothary, V., \& Mitty, J. A. (2014). Sexual partnerships and considerations for HIV antiretroviral pre-exposure prophylaxis utilization among high-risk substance using men who have sex with men. Archives of Sexual Behavior, 43(1), 99-106.

Morrison-Beedy, D., Carey, M. P., \& Tu, X. (2006). Accuracy of audio computerassisted self-interviewing (ACASI) and self-administered questionnaires for the assessment of sexual behavior. AIDS and Behavior, 10(5), 541-552.

Musca, S. C., Kamiejski, R., Nugier, A., Méot, A., Er-Rafiy, A., \& Brauer, M. (2011). Data with hierarchical structure: Impact of intraclass correlation and sample size on type-I error. Frontiers in Psychology, 2, 74. 
SUBSTANCE USE, HIV DISCLOSURE, \& CONDOM USE

Muthén, L.K. and Muthén, B.O. (2012). Mplus user's guide. seventh edition. los angeles, CA: Muthén \& muthén

Newcomb, M. E., Clerkin, E. M., \& Mustanski, B. (2011). Sensation seeking moderates the effects of alcohol and drug use prior to sex on sexual risk in young men who have sex with men. AIDS and Behavior, 15(3), 565-575. doi:10.1007/s10461010-9832-7 [doi]

Norris, J., Stoner, S. A., Hessler, D. M., Zawacki, T., Davis, K. C., George, W. H., . . . Abdallah, D. A. (2009). Influences of sexual sensation seeking, alcohol consumption, and sexual arousal on women's behavioral intentions related to having unprotected sex. Psychology of Addictive Behaviors, 23(1), 14.

Park, C. L., \& Iacocca, M. O. (2014). A stress and coping perspective on health behaviors: Theoretical and methodological considerations. Anxiety, Stress \& Coping, 27(2), 123-137.

Parks, K. A., \& Kennedy, C. L. (2004). Club drugs: Reasons for and consequences of use. Journal of Psychoactive Drugs, 36(3), 295-302.

Parsons, J. T., Kowalczyk, W. J., Botsko, M., Tomassilli, J., \& Golub, S. A. (2013). Aggregate versus day level association between methamphetamine use and HIV medication non-adherence among gay and bisexual men. AIDS and Behavior, $17(4), 1478-1487$.

Parsons, J. T., Schrimshaw, E. W., Bimbi, D. S., Wolitski, R. J., Gómez, C. A., \& Halkitis, P. N. (2005). Consistent, inconsistent, and non-disclosure to casual sexual partners among HIV-seropositive gay and bisexual men. Aids, 19, S87-S97. 
Parsons, J. T., Schrimshaw, E. W., Wolitski, R. J., Halkitis, P. N., Purcell, D. W., Hoff, C. C., \& Gómez, C. A. (2005). Sexual harm reduction practices of HIV-seropositive gay and bisexual men: Serosorting, strategic positioning, and withdrawal before ejaculation. Aids, 19, S13-S25.

Parsons, J. T., VanOra, J., Missildine, W., Purcell, D. W., \& Gómez, C. A. (2004). Positive and negative consequences of HIV disclosure among seropositive injection drug users. AIDS Education and Prevention, 16(5), 459-475.

Patrick, M. E., O’Malley, P. M., Johnston, L. D., Terry-McElrath, Y. M., \& Schulenberg, J. E. (2012). HIV/AIDS risk behaviors and substance use by young adults in the united states. Prevention Science, 13(5), 532-538.

Perry, S. W., Card, C. A., Moffatt, M., Ashman, T., Fishman, B., \& Jacobsberg, L. B. (1994). Self-disclosure of HIV infection to sexual partners after repeated counseling. AIDS Education and Prevention,

Prestage, G., Ven, P. V. d., Grulich, A., Kippax, S., McInnes, D., \& Hendry, O. (2001). Gay men's casual sex encounters: Discussing HIV and using condoms. AIDS Care, 13(3), 277-284.

Przybyla, S. M., Golin, C. E., Widman, L., Grodensky, C. A., Earp, J. A., \& Suchindran, C. (2013). Serostatus disclosure to sexual partners among people living with HIV: Examining the roles of partner characteristics and stigma. AIDS Care, 25(5), 566-572.

Purcell, D. W., Parsons, J. T., Halkitis, P. N., Mizuno, Y., \& Woods, W. J. (2001). Substance use and sexual transmission risk behavior of HIV-positive men who 
SUBSTANCE USE, HIV DISCLOSURE, \& CONDOM USE

have sex with men. Journal of Substance Abuse, 13(1-2), 185-200. doi:S08993289(01)00072-4 [pii]

Quinn, T. C., Wawer, M. J., Sewankambo, N., Serwadda, D., Li, C., Wabwire-Mangen, F., ... Gray, R. H. (2000). Viral load and heterosexual transmission of human immunodeficiency virus type 1. rakai project study group. The New England Journal of Medicine, 342(13), 921-929. doi:10.1056/NEJM200003303421303 [doi]

Radloff, L. S. (1977). The CES-D scale: A self-report depression scale for research in the general population. Applied Psychological Measurement, 1(3), 385-401.

Raudenbush, S. W., Bryk, A. S., \& Congdon, R. (2017).

HLM 7.03 for windows [computer software]. skokie, IL: Scientific software international, inc.

Reilly, T., \& Woo, G. (2001). Predictors of high-risk sexual behavior among people living with HIV/AIDS. AIDS and Behavior, 5(3), 205-217.

Robinson, W. S. (1950). Ecological correlations and the behavior of individuals. American Sociological Review, 15(3), 351-357.

Rutledge, S. E. (2007). Enacting personal HIV disclosure policies for sexual situations: HIV-positive gay men's experiences. Qualitative Health Research, 17(8), 1040-1059.

Saunders, J. B., Aasland, O. G., Babor, T. F., De la Fuente, Juan R, \& Grant, M. (1993). Development of the alcohol use disorders identification test (AUDIT): WHO collaborative project on early detection of persons with harmful alcohol consumption-II. Addiction, 88(6), 791-804. 
SUBSTANCE USE, HIV DISCLOSURE, \& CONDOM USE

Scott-Sheldon, L. A., Walstrom, P., Carey, K. B., Johnson, B. T., Carey, M. P., \& MASH Research Team. (2013). Alcohol use and sexual risk behaviors among individuals infected with HIV: A systematic review and meta-analysis 2012 to early 2013. Current HIV/AIDS Reports, 10(4), 314-323.

Serovich, J. M., Laschober, T. C., Brown, M. J., \& Kimberly, J. A. (2017). Evaluation of HIV disclosure behavior following a randomized controlled disclosure intervention for men who have sex with men living with HIV. Archives of Sexual Behavior, , 1-9.

Serovich, J. M. (2001). A test of two HIV disclosure theories. AIDS Education and Prevention : Official Publication of the International Society for AIDS Education, $13(4), 355-364$.

Serovich, J. M., \& Mosack, K. E. (2003). Reasons for HIV disclosure or nondisclosure to casual sexual partners. AIDS Education and Prevention : Official Publication of the International Society for AIDS Education, 15(1), 70-80.

Simoni, J. M., \& Pantalone, D. W. (2004). Secrets and safety in the age of AIDS: Does HIV disclosure lead to safer sex? Topics in HIV Medicine, 12, 109-118.

Simons, J. S., Maisto, S. A., Wray, T. B., \& Emery, N. N. (2016). Acute effects of intoxication and arousal on approach/avoidance biases toward sexual risk stimuli in heterosexual men. Archives of Sexual Behavior, 45(1), 43-51.

Skinner, H. A. (1982). The drug abuse screening test. Addictive Behaviors, 7(4), 363371. 
Smit, P. J., Brady, M., Carter, M., Fernandes, R., Lamore, L., Meulbroek, M., . . . Rockstroh, J. K. (2012). HIV-related stigma within communities of gay men: A literature review. AIDS Care, 24(4), 405-412.

Stappenbeck, C. A., George, W. H., Staples, J. M., Nguyen, H., Davis, K. C., Kaysen, D., ... Danube, C. L. (2016). In-the-moment dissociation, emotional numbing, and sexual risk: The influence of sexual trauma history, trauma symptoms, and alcohol intoxication. Psychology of Violence, 6(4), 586.

Steele, C. M., \& Josephs, R. A. (1990). Alcohol myopia: Its prized and dangerous effects. American Psychologist, 45(8), 921.

Stein, M. D., Freedberg, K. A., Sullivan, L. M., Savetsky, J., Levenson, S. M., Hingson, R., \& Samet, J. H. (1998). Sexual ethics: Disclosure of HIV-positive status to partners. Archives of Internal Medicine, 158(3), 253-257.

Sullivan, K. M. (2005). Male self-disclosure of HIV-positive serostatus to sex partners: A review of the literature. Journal of the Association of Nurses in AIDS Care, 16(6), 33-47.

Taylor, S. P., \& Leonard, K. E. (1983). Alcohol and human physical aggression. Aggression: Theoretical and Empirical Reviews, 2, 77-101.

Thiede, H., Jenkins, R. A., Carey, J. W., Hutcheson, R., Thomas, K. K., Stall, R. D., .. Golden, M. R. (2009). Determinants of recent HIV infection among seattle-area men who have sex with men. American Journal of Public Health, 99(S1), S157S164.

Vagenas, P., Azar, M. M., Copenhaver, M. M., Springer, S. A., Molina, P. E., \& Altice, F. L. (2015). The impact of alcohol use and related disorders on the HIV continuum 
SUBSTANCE USE, HIV DISCLOSURE, \& CONDOM USE

of care: A systematic review : Alcohol and the HIV continuum of care. Current HIV/AIDS Reports, 12(4), 421-436. doi:10.1007/s11904-015-0285-5 [doi]

Vallabhaneni, S., Li, X., Vittinghoff, E., Donnell, D., Pilcher, C. D., \& Buchbinder, S. P. (2012). Seroadaptive practices: Association with HIV acquisition among HIVnegative men who have sex with men. PLoS One, 7(10), e45718.

Vanable, P. A., McKirnan, D. J., Buchbinder, S. P., Bartholow, B. N., Douglas, J. M.,Jr, Judson, F. N., \& MacQueen, K. M. (2004). Alcohol use and high-risk sexual behavior among men who have sex with men: The effects of consumption level and partner type. Health Psychology : Official Journal of the Division of Health Psychology, American Psychological Association, 23(5), 525-532. doi:10.1037/0278-6133.23.5.525 [doi]

Vosburgh, H. W., Mansergh, G., Sullivan, P. S., \& Purcell, D. W. (2012). A review of the literature on event-level substance use and sexual risk behavior among men who have sex with men. AIDS and Behavior, 16(6), 1394-1410. doi:10.1007/s10461-011-0131-8 [doi]

Vrieze, S. I. (2012). Model selection and psychological theory: A discussion of the differences between the akaike information criterion (AIC) and the bayesian information criterion (BIC). Psychological Methods, 17(2), 228.

Wardell, J. D., Shuper, P. A., Rourke, S. B., \& Hendershot, C. S. (2018). Stigma, coping, and alcohol use severity among people living with HIV: A prospective analysis of bidirectional and mediated associations. Annals of Behavioral Medicine, 
SUBSTANCE USE, HIV DISCLOSURE, \& CONDOM USE

Weinhardt, L. S., \& Carey, M. P. (2000). Does alcohol lead to sexual risk behavior? findings from event-level research. Annual Review of Sex Research, 11(1), 125157.

Wells, B. E., Golub, S. A., \& Parsons, J. T. (2011). An integrated theoretical approach to substance use and risky sexual behavior among men who have sex with men. AIDS and Behavior, 15(3), 509-520.

Williams, E. C., McGinnis, K. A., Bobb, J. F., Rubinsky, A. D., Lapham, G. T., Skanderson, M., ... Bryant, K. J. (2018). Changes in alcohol use associated with changes in HIV disease severity over time: A national longitudinal study in the veterans aging cohort. Drug and Alcohol Dependence,

Wolitski, R. J., Bailey, C. J., O'Leary, A., Gómez, C. A., \& Parsons, J. T. (2003). Selfperceived responsibility of HIV-seropositive men who have sex with men for preventing HIV transmission. AIDS and Behavior, 7(4), 363-372.

Yi, H., Sandfort, T. G., \& Shidlo, A. (2010). Effects of disengagement coping with HIV risk on unprotected sex among HIV-negative gay men in new york city. Health Psychology, 29(2), 205.

Young, R., OEI, T. P., \& Knight, R. G. (1990). The tension reduction hypothesis revisited: An alcohol expectancy perspective. Addiction, 85(1), 31-40. 


\section{TABLES \& FIGURES}

Table 1: Participant Demographics

\begin{tabular}{|c|c|}
\hline 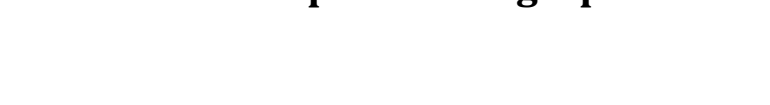 & $\begin{array}{c}N=251 \\
\text { Mean (SD)/ N (\%) }\end{array}$ \\
\hline Age (Years) & $42.0(10.1)$ \\
\hline \multicolumn{2}{|l|}{ Gender } \\
\hline Male & $213(84.9 \%)$ \\
\hline Female & $38(15.1 \%)$ \\
\hline Trans Male & $10(4.0 \%)$ \\
\hline Trans Female & $8(3.2 \%)$ \\
\hline \multicolumn{2}{|l|}{ Race/Ethnicity } \\
\hline Black/African American & $230(91.6 \%)$ \\
\hline White & $14(5.6 \%)$ \\
\hline Hispanic/Latino & $2(0.8 \%)$ \\
\hline Other & $5(2.0 \%)$ \\
\hline \multicolumn{2}{|l|}{ Household Annual Income } \\
\hline Under $\$ 10,000$ & $158(62.9 \%)$ \\
\hline$\$ 11,000-\$ 20,000$ & $57(22.7 \%)$ \\
\hline$\$ 21,000-\$ 30,000$ & $25(10.0 \%)$ \\
\hline Over $\$ 30,000$ & $10(4.0 \%)$ \\
\hline \multicolumn{2}{|l|}{ Healthcare } \\
\hline Coverage in past 2 years & $179(71.3 \%)$ \\
\hline No coverage past 2 years & $72(28.7 \%)$ \\
\hline \multicolumn{2}{|l|}{ Employment Status } \\
\hline Unemployed & $81(32.3 \%)$ \\
\hline Working & $48(19.1 \%)$ \\
\hline On disability & $109(43.4 \%)$ \\
\hline Student & $6(2.4 \%)$ \\
\hline Other & $7(2.8 \%)$ \\
\hline \multicolumn{2}{|l|}{ Education } \\
\hline $7^{\text {th }}-11^{\text {th }}$ grade & $43(17.1 \%)$ \\
\hline $12^{\text {th }}$ grade or GED & $74(29.5 \%)$ \\
\hline Some College & $81(32.3 \%)$ \\
\hline Completed College & $53(21.1 \%)$ \\
\hline Years since HIV Diagnosis & $12.3(8.3)$ \\
\hline CES-D $(0-60)$ & $17.6(12.2)$ \\
\hline \multicolumn{2}{|l|}{ AUDIT (0-40) } \\
\hline 0 & $74(29.5 \%)$ \\
\hline $1-8$ & $135(53.7 \%)$ \\
\hline $8+$ & $39(15.5 \%)$ \\
\hline Drug Abuse Screening Test (DAST) $(0-10)$ & $1.5(2.0)$ \\
\hline
\end{tabular}




\begin{tabular}{lc}
\hline Drug Use (Positive urine tox screen \%) & $70(27.9 \%)$ \\
THC (Cannabis) & $70(27.9 \%)$ \\
Cocaine & $24(9.6 \%)$ \\
Benzodizepines & $9(3.6 \%)$ \\
Opiates & $9(3.6 \%)$ \\
Methamphetamine & $7(2.8 \%)$ \\
Amphetamines & $7(2.8 \%)$ \\
Oxycontin & $3(1.2 \%)$ \\
MDMA & $2(0.8 \%)$ \\
PCP & $1(0.4 \%)$ \\
Barbituates & $1(0.4 \%)$ \\
Methadone & \\
\hline Number of first-time non-HIV-positive & \\
sexual partners in 28-day study period & $131(52.2 \%)$ \\
1 & $63(25.1 \%)$ \\
2 & $22(8.8 \%)$ \\
3 & $12(4.8 \%)$ \\
4 & $23(9.2 \%)$ \\
\hline
\end{tabular}

Table 2: Sexual Event Characteristics

(Event $\mathrm{N}=529$ )

\begin{tabular}{l|ccc|c}
$\begin{array}{l}\text { Participant Gender } \\
\text { (PLWH) }\end{array}$ & \multicolumn{3}{|c|}{ Man } & Woman \\
\hline $\begin{array}{l}\text { Partner Gender } \\
\text { (HIV-/unknown HIV } \\
\text { status partner) }\end{array}$ & Man & Woman & Transgender & Man \\
(348 events) & (100 events) & events) & (67 events) \\
\hline $\begin{array}{l}\text { Participant and/or } \\
\text { partner used } \\
\text { substances }\end{array}$ & $166(47.7 \%)$ & $46(46.0 \%)$ & $7(50 \%)$ & $28(41.8 \%)$ \\
$\begin{array}{l}\text { Participant Used } \\
\text { Substances }\end{array}$ & $132(37.9 \%)$ & $30(30.0 \%)$ & $6(42.9 \%)$ & $25(37.3 \%)$ \\
$\begin{array}{l}\text { Partner Used } \\
\text { Substances }\end{array}$ & $115(33.0 \%)$ & $28(28.0 \%)$ & $5(35.7 \%)$ & $12(17.9 \%)$ \\
$\begin{array}{l}\text { Participant } \\
\text { disclosed positive }\end{array}$ & $106(30.5 \%)$ & $34(34.0 \%)$ & $7(50 \%)$ & $23(34.3 \%)$ \\
$\begin{array}{l}\text { HIV serostatus } \\
\text { Condom Used }\end{array}$ & $151(43.4 \%)$ & $71(71.0 \%)$ & $9(64.3 \%)$ & $31(46.3 \%)$ \\
\hline
\end{tabular}


Table 3: Within-Person Mediation Model

\begin{tabular}{|c|c|c|c|c|c|}
\hline & OR & Estimate (95\% CI) & SE & $\mathrm{t}$ & $p$ \\
\hline \multicolumn{6}{|l|}{ Within-Person Effects } \\
\hline \multicolumn{6}{|l|}{ Disclosure } \\
\hline $\begin{array}{l}\text { Either partner used } \\
\text { substances (Path A) }\end{array}$ & 0.46 & $-0.79(-1.53,-0.05)$ & 0.38 & -2.09 & 0.037 \\
\hline Partner gender & 1.81 & $0.59(-0.34,1.53)$ & 0.48 & 1.25 & 0.212 \\
\hline \multicolumn{6}{|l|}{ Condom Use } \\
\hline $\begin{array}{l}\text { Either partner used } \\
\text { substances (Direct Effect) }\end{array}$ & 1.18 & $0.16(-0.50,0.82)$ & 0.34 & 0.48 & 0.630 \\
\hline $\begin{array}{l}\text { Participant disclosed HIV+ } \\
\text { status (Path B) }\end{array}$ & 1.01 & $0.01(-0.68,0.69)$ & 0.35 & 0.01 & 0.990 \\
\hline Partner Gender & 4.43 & $1.49(0.56,2.42)$ & 0.47 & 3.14 & 0.002 \\
\hline \multicolumn{6}{|l|}{ Between-Person Effects } \\
\hline \multicolumn{6}{|l|}{ Disclosure } \\
\hline Participant gender & & $0.57(-0.91,2.05)$ & 0.76 & 0.76 & 0.451 \\
\hline Participant age & & $0.03(-0.02,0.09)$ & 0.03 & 1.14 & 0.256 \\
\hline \multicolumn{6}{|l|}{ Condom use } \\
\hline Participant gender & & $0.18(-0.95,1.32)$ & 0.58 & 0.32 & 0.753 \\
\hline Participant age & & $-0.03(-0.07,0.01)$ & 0.02 & -1.49 & 0.137 \\
\hline \multicolumn{6}{|l|}{ Test of indirect effect } \\
\hline Path A*Path B & & $-0.00(-0.55,0.54)$ & 0.28 & -0.01 & 0.990 \\
\hline
\end{tabular}

AIC: $1214.87 ;$ BIC: 1270.39

OR: odds ratio; 95\% CI: 95\% confidence interval. SE: standard error.

Bold denotes statistically significant effect at $\mathrm{p}<0.05$ level. 
SUBSTANCE USE, HIV DISCLOSURE, \& CONDOM USE

Table 4A: Between-Person Mediation Model-Alcohol Use (AUDIT)

\begin{tabular}{lcccc} 
& Estimate (95\% CI) & SE & t & $p$ \\
\hline Between-Person Effects & & & & \\
\hline Disclosure & $\mathbf{0 . 0 1}(-\mathbf{0 . 0 2}, \mathbf{- 0 . 0 0})$ & $\mathbf{0 . 0 4}$ & $\mathbf{- 2 . 5 9}$ & $\mathbf{0 . 0 1 0}$ \\
AUDIT (Path A) & $0.05(-0.12,0.21)$ & 0.08 & 0.56 & 0.576 \\
Participant gender & $0.00(-0.00,0.01)$ & 0.00 & 1.39 & 0.166 \\
Participant age & & & & \\
& & & & \\
Condom Use & $\mathbf{- 0 . 0 7 ( - \mathbf { 0 . 1 4 } , \mathbf { 0 . 0 0 } )}$ & $\mathbf{0 . 0 4}$ & $\mathbf{- 1 . 9 3}$ & $\mathbf{0 . 0 5 4}$ \\
AUDIT (Direct Effect) & $0.65(-0.25,1.54)$ & 0.46 & 1.42 & 0.157 \\
Participant disclosed HIV+ & & & \\
status (Path B) & $-0.32(-1.45,0.80)$ & 0.58 & -0.56 & 0.573 \\
Participant gender & $-0.02(-0.06,0.02)$ & 0.02 & -1.01 & 0.311 \\
Participant age & & & & \\
& & & & \\
\hline Test of indirect effect & $-0.01(-0.02,0.00)$ & 0.01 & -1.21 & 0.227
\end{tabular}

AIC: $1284.41 ;$ BIC: 1339.93

OR: odds ratio; $95 \% \mathrm{CI}$ : 95\% confidence interval. SE: standard error.

Bold denotes statistically significant effect at $\mathrm{p}<0.05$ level.

Table 4B: Between-Person Mediation Model-Illicit Drug Use (DAST)

\begin{tabular}{lcccc} 
& Estimate $(95 \% \mathrm{CI})$ & $\mathrm{SE}$ & $\mathrm{t}$ & $p$ \\
\hline Between-Person Effects & & & & \\
\hline Disclosure & $\mathbf{- 0 . 0 3 ( - \mathbf { 0 . 0 5 } , \mathbf { - 0 . 0 1 } )}$ & $\mathbf{0 . 0 1}$ & $\mathbf{- 2 . 3 4}$ & $\mathbf{0 . 0 1 9}$ \\
DAST (Path A) & $0.05(-0.12,0.21)$ & 0.08 & 0.56 & 0.579 \\
Participant gender & $0.01(-0.00,0.01)$ & 0.00 & 1.59 & 0.113 \\
Participant age & & & & \\
& & & & \\
Condom Use & $-0.16(-0.34,0.03)$ & 0.09 & -1.68 & 0.094 \\
DAST (Direct Effect) & $0.68(-0.23,1.58)$ & 0.46 & 1.47 & 0.143 \\
Participant disclosed HIV+ & & & \\
status (Path B) & $-0.33(-1.46,0.80)$ & 0.58 & -0.57 & 0.568 \\
Participant gender & $-0.02(-0.06,0.02)$ & 0.02 & -0.87 & 0.387 \\
Participant age & & & & \\
& & & & \\
\hline Test of indirect effect & $-0.02(-0.05,0.01)$ & 0.02 & -1.23 & 0.221
\end{tabular}

AIC: 2020.90; BIC: 2076.42

95\% CI: 95\% confidence interval. SE: standard error.

Bold denotes statistically significant effect at $\mathrm{p}<0.05$ level. 
SUBSTANCE USE, HIV DISCLOSURE, \& CONDOM USE

Table 4C: Between-Person Mediation Model-Frequency of Using Substances at Time of Sex

\begin{tabular}{|c|c|c|c|c|}
\hline & Estimate $(95 \% \mathrm{CI})$ & SE & $\mathrm{t}$ & $p$ \\
\hline \multicolumn{5}{|l|}{ Between-Person Effects } \\
\hline \multicolumn{5}{|l|}{ Disclosure } \\
\hline $\begin{array}{l}\text { Participant substance use } \\
\text { frequency (Path A) }\end{array}$ & $-0.17(-0.29,-0.04)$ & 0.06 & -2.59 & 0.009 \\
\hline Participant gender & $0.05(-0.11,0.20)$ & 0.08 & 0.61 & 0.542 \\
\hline Participant age & $0.00(-0.00,0.01)$ & 0.00 & 1.24 & 0.216 \\
\hline \multicolumn{5}{|l|}{ Condom Use } \\
\hline $\begin{array}{l}\text { Participant substances use } \\
\text { frequency (Direct Effect) }\end{array}$ & $-0.28(-1.26,0.71)$ & 0.50 & -0.55 & 0.580 \\
\hline $\begin{array}{l}\text { Participant disclosed HIV+ } \\
\text { status (Path B) }\end{array}$ & $0.71(-0.20,1.62)$ & 0.47 & 1.53 & 0.126 \\
\hline Participant gender & $-0.24(-1.50,1.01)$ & 0.64 & -0.38 & 0.706 \\
\hline Participant age & $-0.02(-0.06,0.02)$ & 0.02 & -0.88 & 0.376 \\
\hline \multicolumn{5}{|l|}{ Test of indirect effect } \\
\hline Path A*Path B & $-0.12(-0.29,0.06)$ & 0.09 & -1.34 & 0.182 \\
\hline
\end{tabular}

AIC: $3330.01 \quad$ BIC: 3402.62

95\% CI: 95\% confidence interval. SE: standard error.

Bold denotes statistically significant effect at $\mathrm{p}<0.05$ level. 
Table 5A: Path A Model Predicting Participant HIV Disclosure from EventLevel Substance Use (Participant using)

\begin{tabular}{lccccc} 
& OR & Estimate $(95 \%$ CI $)$ & SE & t & $p$ \\
\hline Within-Person Effects & & & & & \\
\hline $\begin{array}{l}\text { Participant used } \\
\text { substances } \\
\text { Partner gender }\end{array}$ & 0.67 & $-0.40(-1.08,0.28)$ & 0.35 & -1.16 & 0.25 \\
& 1.80 & $0.59(-0.34,1.52)$ & 0.47 & 1.24 & 0.21 \\
\hline Between-Person Effects & & & & & \\
\hline $\begin{array}{l}\text { Participant gender } \\
\text { Participant age }\end{array}$ & $0.77(-0.70,2.24)$ & 0.75 & 1.03 & 0.30 \\
& & $0.03(-0.02,0.08)$ & 0.03 & 1.10 & 0.27
\end{tabular}

AIC: $1304.41 ;$ BIC: 1338.6

OR: odds ratio; 95\% CI: 95\% confidence interval. SE: standard error.

Bold denotes statistically significant effect at $\mathrm{p}<0.05$ level.

Table 5B: Path A Model Predicting Participant HIV Disclosure from EventLevel Substance Use (Both partners using)

\begin{tabular}{lccccc} 
& OR & Estimate $(95 \%$ CI $)$ & SE & t & $p$ \\
\hline Within-Person Effects & & & & & \\
\hline Both used substances & 0.96 & $-0.04(-0.97,0.89)$ & 0.47 & -0.09 & 0.93 \\
Partner gender & 1.80 & $0.59(-0.35,1.53)$ & 0.48 & 1.22 & 0.22 \\
& & & & & \\
\hline Between-Person Effects & & $0.70(-0.78,2.18)$ & 0.76 & 0.93 & 0.35 \\
\hline Participant gender & & $0.03(-0.03,0.08)$ & 0.03 & 0.98 & 0.32 \\
Participant age & & & &
\end{tabular}

AIC: $1110.25 ;$ BIC: 1144.42

OR: odds ratio; 95\% CI: 95\% confidence interval. SE: standard error.

Bold denotes statistically significant effect at $\mathrm{p}<0.05$ level

Table 5C: Path A Model Predicting Participant HIV Disclosure from EventLevel Substance Use (Sexual partner using)

\begin{tabular}{lccccc} 
& OR & Estimate $(95 \% \mathrm{CI})$ & SE & $\mathrm{t}$ & $p$ \\
\hline Within-Person Effects & & & & & \\
\hline Partner used substances & 0.70 & $-0.36(-1.07,0.36)$ & 0.37 & -0.98 & 0.33 \\
Partner gender & 1.77 & $0.57(-0.35,1.50)$ & 0.47 & 1.21 & 0.23 \\
& & & & & \\
\hline Between-Person Effects & & $0.63(-0.83,2.10)$ & 0.75 & 0.85 & 0.40 \\
\hline Participant gender & & $0.03(-0.03,0.08)$ & 0.03 & 0.99 & 0.32 \\
Participant age & &
\end{tabular}

AIC: $1257.92 ; \quad$ BIC: 1292.11

OR: odds ratio; 95\% CI: 95\% confidence interval. SE: standard error.

Bold denotes statistically significant effect at $\mathrm{p}<0.05$ level 
SUBSTANCE USE, HIV DISCLOSURE, \& CONDOM USE

Table 6: Path B Model Predicting Condom Use from Event-Level HIV Disclosure

\begin{tabular}{lccccc} 
& OR & Estimate $(95 \% \mathrm{CI})$ & $\mathrm{SE}$ & $\mathrm{t}$ & $p$ \\
\hline Within-Person Effects & & & & & \\
\hline Participant HIV Disclosure & $\mathbf{0 . 3 9}$ & $\mathbf{- 0 . 9 4} \mathbf{( - 1 . 6 2 , - 0 . 2 6 )}$ & $\mathbf{0 . 4 1}$ & $\mathbf{- 2 . 2 7}$ & $\mathbf{0 . 0 2}$ \\
Partner gender & 4.51 & $1.51(0.74,2.27)$ & 0.47 & 3.23 & 0.001 \\
& & & & & \\
\hline Between-Person Effects & & $\mathbf{1 . 6 7}(\mathbf{0 . 6 5}, \mathbf{2 . 6 9})$ & $\mathbf{0 . 6 2}$ & $\mathbf{2 . 6 9}$ & $\mathbf{0 . 0 0 7}$ \\
\hline Disclosure Frequency & & $0.02(-0.92,0.96)$ & 0.57 & 0.04 & 0.97 \\
Participant gender & & $-0.03(-0.07,0.00)$ & 0.02 & -1.67 & 0.10 \\
Participant age & &
\end{tabular}

AIC: 1656.42 BIC: 1703.41

OR: odds ratio; $95 \% \mathrm{CI}$ : 95\% confidence interval. SE: standard error.

Bold denotes statistically significant effect at $\mathrm{p}<0.05$ level

Figure 1: Proposed Mediation Model

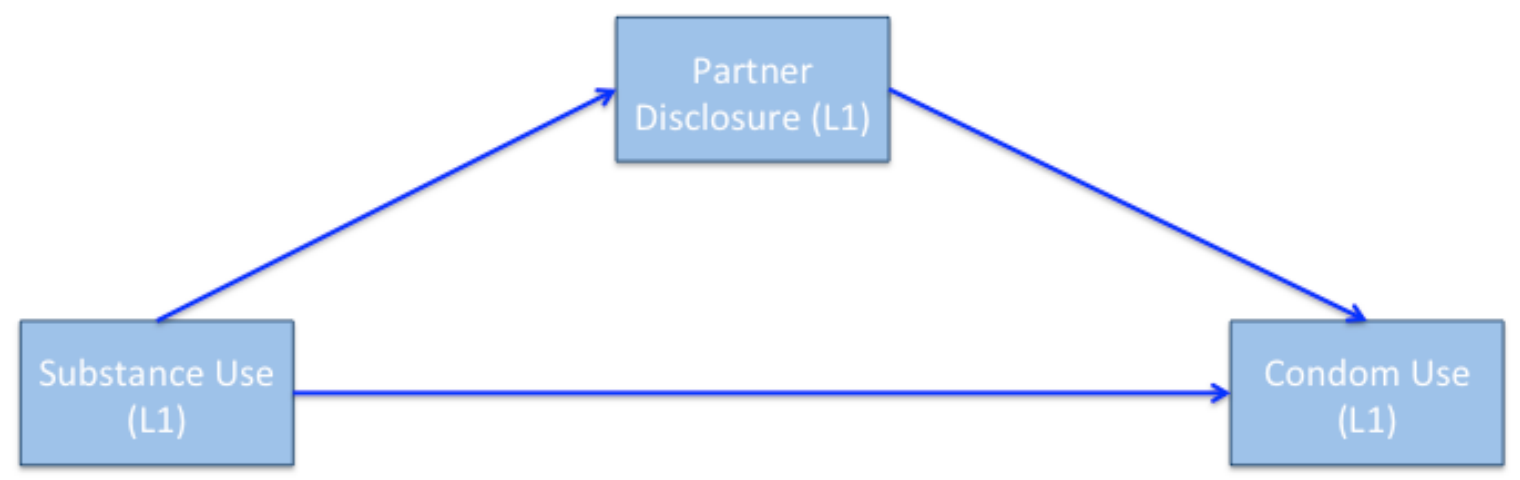




\section{APPENDIX: MPlus Code for Event-Level Analyses}

\section{Within-Person Mediation Model (Results Reported in Table 3)}

INPUT INSTRUCTIONS

TITLE: Substance use, disclosure, and condom use mediation - Within-person DATA: FILE IS Data.csv;

VARIABLE: NAMES ARE id condomuse substanceuse disclosure partnergender participantgender age;

USEVAR ARE id condomuse substanceuse disclosure partnergender participantgender age;

CATEGORICAL ARE disclosure condomuse;

CLUSTER = id;

WITHIN = substanceuse partnergender;

BETWEEN = participantgender age;

Missing are all (-99);

ANALYSIS: TYPE = twolevel random;

ESTIMATOR=mlr;

MODEL: \%WITHIN\%

disclosure ON substanceuse (awithin);

condomuse ON disclosure (bwithin);

condomuse ON substanceuse;

condomuse ON partnergender;

disclosure ON partnergender;

\%BETWEEN\%

disclosure condomuse;

disclosure ON participantgender;

discosure $\mathrm{ON}$ age;

condomuse ON participantgender;

condomuse ON age;

MODEL CONSTRAINT:

NEW (indw);

indw=awithin*bwithin;

OUTPUT: sampstat cinterval; 


\section{Between-Person Mediation Model (Results Reported in Tables 4 A-C)}

Four model versions alternately utilized between-person "substanceuse" terms derived from a) AUDIT score, b) DAST score, c) proportion of events using substances, and d) number of positive drug screens at study entry

\section{INPUT INSTRUCTIONS}

TITLE: Substance use, disclosure, and condom use mediation - Between-person DATA: FILE IS Data.csv;

VARIABLE: NAMES ARE id condomuse substanceuse disclosure partnergender participantgender age;

USEVAR ARE id condomuse substanceuse disclosure partnergender participantgender age;

CATEGORICAL ARE condomuse;

CLUSTER = id;

WITHIN =;

BETWEEN = substanceuse disclosure participantgender age;

Missing are all (-99);

ANALYSIS: TYPE = twolevel random;

ESTIMATOR $=\mathrm{mlr}$;

MODEL: \%WITHIN\%

\%BETWEEN\%

substanceuse disclosure condomuse gender age;

disclosure ON substanceuse (abetween);

condomuse ON disclosure (bbetween);

condomuse ON substanceuse;

condomuse ON participantgender;

condomuse $\mathrm{ON}$ age;

disclosure ON participantgender;

discosure $\mathrm{ON}$ age;

MODEL CONSTRAINT:

NEW (indb);

indv=abetween*bbetween;

OUTPUT: sampstat cinterval; 


\section{Path A Model Predicting Participant HIV Disclosure from Event-Level Substance Use (Results Reported in Tables 5 A-C)}

Model versions A-C alternately utilized independent variable "substanceuse" terms derived from event level reporting of a) Participant Using Substances, b) Both Partners Using Substances, and c) Participant's Sexual Partner Using Substances

INPUT INSTRUCTIONS

TITLE: Path A: Event-level substance use and disclosure DATA: FILE IS Data.csv;

VARIABLE: NAMES ARE id condomuse substanceuse disclosure partnergender participantgender age;

USEVAR ARE id substanceuse disclosure partnergender participantgender age; CATEGORICAL ARE disclosure;

CLUSTER = id;

WITHIN = substanceuse parntergender;

BETWEEN = participantgender age;

Missing are all (-99);

ANALYSIS: TYPE = twolevel random;

ESTIMATOR=mlr;

MODEL: \%WITHIN\%

substanceuse;

disclosure ON substanceuse;

disclosure ON partnergender;

\%BETWEEN\%

disclosure;

disclosure ON participantgender;

disclosure ON age;

OUTPUT: sampstat cinterval; 


\section{Path B Model Predicting Condom Use from Event-Level HIV Disclosure- Within-Person and Between-person terms included (Results Reported in Table 6)}

\section{INPUT INSTRUCTIONS}

TITLE: Path B: Event-level disclosure and condom use DATA: FILE IS Data.csv;

VARIABLE: NAMES ARE id condomuse disclosure disclosurefrequency partnergender participantgender age;

USEVAR ARE id condomuse disclosure disclosurefrequency partnergender participantgender age;

CATEGORICAL ARE condomuse;

CLUSTER = id;

WITHIN = disclosure parntergender;

BETWEEN = disclosurefrequency participantgender age;

Missing are all (-99);

ANALYSIS: TYPE = twolevel random;

ESTIMATOR $=\mathrm{mlr}$;

MODEL: \%WITHIN\%

disclosure;

condomuse ON disclosure;

condomuse ON partnergender;

\%BETWEEN\%

condomuse;

condomuse $\mathrm{ON}$ disclosurefrequency;

condomuse $\mathrm{ON}$ participantgender;

condomuse ON age;

OUTPUT: sampstat cinterval; 


\section{Main effect subgroup analyses: disclosure status}

Identical model run in subgroups of a) events in which HIV disclosure was reported and b) events in which HIV non-disclosure was reported

\section{INPUT INSTRUCTIONS}

TITLE: Substance use, disclosure, and condom use mediation - Between-person DATA: FILE IS Data.csv;

VARIABLE: NAMES ARE id condomuse substanceuse disclosure partnergender participantgender age;

USEVAR ARE id condomuse substanceuse disclosure partnergender participantgender age;

CATEGORICAL ARE condomuse;

CLUSTER = id;

WITHIN = substanceuse parntergender;

BETWEEN = participantgender age;

Missing are all (-99);

ANALYSIS: TYPE = twolevel random;

ESTIMATOR=mlr;

MODEL: \%WITHIN\%

substanceuse;

condomuse ON substanceuse;

condomuse $\mathrm{ON}$ partnergender;

\%BETWEEN\%

substanceuse;

condomuse ON participantgender;

condomuse $\mathrm{ON}$ age;

OUTPUT: sampstat cinterval; 


\section{Main effect subgroup analyses by gender and partner gender}

To examine potential moderating effects of gender/partner gender, the full mediation model reported in Table 3 was applied separately to participant gender/partner gender subgroups, with gender and partner gender terms removed (displayed below). The identical model was run in a) MSM, b) MSW, and c) WSM participant subgroups.

INPUT INSTRUCTIONS

TITLE: Substance use, disclosure, and condom use mediation - Within-person DATA: FILE IS Data.csv;

VARIABLE: NAMES ARE id condomuse substanceuse disclosure age; USEVAR ARE id condomuse substanceuse disclosure age;

CATEGORICAL ARE disclosure condomuse;

CLUSTER = id;

WITHIN = substanceuse;

BETWEEN = age;

Missing are all (-99);

ANALYSIS: TYPE = twolevel random;

ESTIMATOR=mlr;

MODEL: \%WITHIN\%

disclosure ON substanceuse (awithin); condomuse ON disclosure (bwithin);

condomuse ON substanceuse;

$\%$ BETWEEN\%

disclosure condomuse;

disclosure $\mathrm{ON}$ age;

condomuse ON age;

MODEL CONSTRAINT:

NEW (indw);

indw=awithin*bwithin;

OUTPUT: sampstat cinterval; 